\title{
Iluminação natural e ofuscamento: estudo de caso em edifícios residenciais multipavimentos
}

\author{
Daylighting and glare: case study in multi-storey \\ residential buildings
}

\section{Lilianne de Queiroz Leal Solange Maria Leder}

\section{Resumo}

$\mathbf{E}$ ste trabalho tem como objetivo analisar a obstrução do céu no meio urbano e seu impacto na iluminação natural e no ofuscamento. Ambientes internos em um edifício residencial multipavimentos inseridos em um clima quente e úmido foram analisados. $\mathrm{O}$ desempenho da iluminação natural e do ofuscamento nos ambientes de análise foi obtido com o emprego da simulação dinâmica da luz natural, com o programa Daysim e o aplicativo Evalglare.Foram analisados 120 ambientes, resultantes da combinação das variáveis: (a) obstrução do entorno;(b) refletância das superfícies do entorno;(c) proteção solar nos edifícios do entorno;(d) altura do pavimento; e (e) orientação geográfica. Os indicadores de desempenho da iluminação natural e do ofuscamento empregados foram: a iluminância útil (UDI); a iluminância excessiva (eUDI); e a probabilidade de ofuscamento da luz natural (DGP). Entre os principais resultados destacam-se: (a) redução da iluminância útil (aUDI) no percentual de área iluminada de 21,5\% no cenário de máxima obstrução e de $40 \%$ nos ambientes localizados no térreo; (b) aumento da área iluminada em 8,5\%, com um coeficiente de reflexão elevado, porém com impacto menor no pavimento térreo, de apenas 3\%; (c) diminuição da probabilidade de ofuscamento nos cenários com obstrução do entorno; (d) redução das iluminâncias excessivas e do ofuscamento com o sombreamento causado pelos elementos de proteção solar horizontal inseridos nos edifícios do entorno; e (e) chances de ofuscamento e refletividade das superfícies verticais do entorno como variáveis diretamente proporcionais.

Palavras-chave: Iluminação natural. Ofuscamento. Simulaçãocomputacional.
${ }^{1}$ Lilianne de Queiroz Leal 1 Universidade Federal de Campina Grande Pombal - PB - Brasil

2Solange Maria Leder ${ }^{2}$ Universidade Federal da Paraíba João Pessoa - PB - Brasil

Recebido em 19/09/17 Aceito em 09/01/18

\begin{abstract}
The aim of this study is to investigate sky obstruction in the urban fabric and its impact on daylighting and glare. Rooms in a multi-storey residential building were analysed using data from a hot and humid climate. The daylighting performance and glare levels inside the analysed rooms were accessed through climate-based simulations, using Daysim and Evalglare. A total of 120 room variations were studied, resulting from the combination of the following variables: (a) urban fabric scenarios, (b) reflection coefficient on the buildings, (c) horizontal sun shading on neighbouring facades and windows, d) floor height, and finally e) geographic orientation. The daylighting and glare performance parameters used were: useful illuminance (UDI), excessive illuminance (eUDI) and daylight glare probability $(D G P)$. The main results highlighted in this study are: (a) a reduction of aUDI by $21.5 \%$ with the maximum obstruction scenario and by $40 \%$ in rooms located on the ground floor; $(b)$ a higher reflection coefficient increased the illuminated area by $8.5 \%$, with less effect on the ground floor, at only 3\%; (c) a lower probability of glare was observed with higher sky obstruction; d) reduction of excessive illuminance and glare with the shading caused by the insertion of horizontal sun shading on neighbouring facades; (e) glare chance and a high reflection coefficient on the buildings are directly proportional variables.

Keywords: Daylighting. Glare. Computer simulation.
\end{abstract}




\section{Introdução}

A forma, a altura, o espaçamento entre as edificações, o coeficiente de reflexão, entre outras características dos edifícios, são variáveis que afetam a disponibilidade de luz natural no meio urbano e, consequentemente, no ambiente interno. A quantidade de luz que penetra no ambiente interno através da abertura depende, além de sua dimensão, das condições do entorno. Segundo Reinhart (2014), nas cidades de Boston, Seattle e Phoenix, a iluminação natural em um ambiente de escritório com uma abertura lateral é reduzida em $20 \%$ para cada $15^{\circ}$ de obstrução da linha de visão do céu. Para um ângulo inferior a $15 \%$ ou uma obstrução maior que $75 \%$, a luz natural no interior do ambiente pode não atender aos níveis mínimos ou chegar a ser inexistente.

A associação entre o grau de obstrução do entorno, o sombreamento, a radiação solar e o coeficiente de reflexão das superfícies externas resulta em diferenças significativas nos níveis de iluminância interna (TSANGRASSOULIS et al., 1999; LI et al., 2010). O montante de luz natural que um edifício recebe em suas faces externas depende da orientação, da forma, do entorno e também da refletividade das superfícies adjacentes (BAKER; FANCHIOTTI; STEEMERS, 1993; ORAL; YENER; BAYAZIT, 2004). Assim, a componente refletida no entorno pode ser uma variável atenuante do efeito da obstrução daquele. Robbins (1986) considera obstruções que bloqueiam mais de $50 \%$ do campo de visão como "refletoras" e importantes fontes de iluminação natural; por outro lado, se a refletividade for superior a $60 \%$, a probabilidade de ofuscamento será maior.

O impacto das obstruções decorrentes da configuração urbana, tais como a altura das edificações, a largura das vias, o espaçamento entre as edificações e o coeficiente de reflexão das superfícies externas, tem sido investigado por diversos autores, como Tsangrassoulis et al. (1999), Ünver et al. (2003), Compagnon (2004), Ng (2005), Ratti, Baker e Steemers (2005), Leder, Pereira e Claro (2008), Scalco, Pereira e Claro (2010) e Scalco e Pereira (2016).

A latitude e o tipo de céu predominante, contudo, são variáveis que suscitam diferentes condições de iluminação, inclusive em um mesmo cenário urbano. Esse fato justifica a necessidade de ampliar estudos dessa natureza em contextos específicos. Assim, o presente trabalho tem como objetivo avaliar a influência de variáveis do entorno nos níveis de iluminação e ofuscamento de ambientes internos inseridos no clima tropical (baixa latitude).

\section{Iluminação natural e obstrução do entorno}

O efeito da obstrução do entorno na iluminação natural de ambientes internos tem sido investigado especialmente através da simulação computacional, que viabiliza a análise de situações complexas que envolvem grande número de variáveis (COMPAGNON, 2004; NG, 2005; RATTI; BAKER; STEEMERS, 2005; LEDER; PEREIRA; CLARO, 2008; SCALCO; PEREIRA; CLARO, 2010). Estudos dessa natureza incluem, além do ambiente interno, cenários de ocupação do meio urbano, nos quais são considerados como variáveis traçado urbano, taxa de ocupação, gabarito, coeficiente de reflexão das superfícies externas, espaçamento entre as edificações, etc.

$\mathrm{Ng}$ e Wong (2004) identificaram que, para uma mesma densidade construída em Hong Kong, com a variação na altura das edificações é possível melhorar o desempenho da iluminação natural de $20 \%$ a $30 \%$. Alterações lumínicas podem, sobretudo, ser percebidas quanto ao intervalo ou espaçamento entre as edificações. Já os cenários com parcelamento regular, gabarito superior a cinco pavimentos e taxa de ocupação com $75 \%$ culminam em maior percentual de impactos negativos sobre a luz natural, conforme método proposto por Scalco e Pereira (2016), para análise do impacto da vizinhança na iluminação natural sob condições de céu encoberto no Brasil.

O coeficiente de reflexão das superfícies do entorno é uma variável de grande influência. No cálculo da iluminação natural pelo método do fluxo dividido, a componente refletida é uma das três variáveis utilizadas (HOPKINSON; PETHERBRIDGE; LONGMORE, 1966; NBR 15215-3 (ABNT, 2005)). $\mathrm{Na}$ análise de Chatzidimitriou e Yannas (2004) sobre a iluminação natural em um cenário urbano foram identificados maiores níveis de iluminação nas fachadas voltadas para as ruas quando comparado com as fachadas voltadas para o meio da quadra. Um dos fatores responsáveis por essa diferença seria que aquelas têm coeficiente de reflexão maior que essas. Para Mesa et al. (2004), em Mendonza, na Argentina, uma superfície refletora próxima pode incrementar a disponibilidade de luz ao nível da fachada (superfícies verticais) em até $110 \%$ para condições de céu claro.

Em relação às superfícies horizontais, Lam (1986) destaca a luz solar refletida no solo como uma importante fonte de luz natural, especialmente em locais de baixa latitude. Cabús (2004), em um 
estudosobre a contribuição da luz refletida no solo na iluminação de um ambiente em Maceió, conclui que uma parte significativa de luz natural que atinge o plano de trabalho é proveniente da reflexão do solo. Ambientes inseridos em local de baixa latitude, cuja componente refletida variou entre $10 \%$ e $40 \%$, atingiram os maiores percentuais em função da refletividade da luz direta na superfície horizontal. Já os dispositivos de proteção solar, como as marquises, podem admitir altos níveis de iluminância natural e atingir espaços mais profundos. Regiões tropicais, onde a luminância média do céu é alta, como em Singapura, o ofuscamento pode ser crítico, dependendo não apenas da área exposta da janela, mas também da luminância exterior/interior e do ângulo de visão do observador (WONG; ISTIADJI, 2003).

\section{Indicadores de desempenho da iluminação natural e do ofuscamento}

Os indicadores dinâmicos de desempenho da luz natural são parâmetros de predição da eficiência da iluminação baseados em arquivos climáticos (Climate-Based Daylight Modelling - CBDM). Ao contrário das métricas estáticas que geram valores absolutos de luminância e iluminância mediante uma condição de céu específica, os indicadores dinâmicos foram desenvolvidos com o intuito de quantificar condições lumínicas naturais considerando variações estacionárias ocorridas ao longo de um ano. Com base em preferências de usuários de ambientes de escritório, Mardaljevic et al. (2011) destacam as métricas autonomia da luz natural (Daylight Autonomy - DA) e iluminância natural útil (Useful Daylight Illuminance - UDI).

A métrica DA consiste no percentual de horas/ano em que um nível de iluminância mínimo exigido é mantido no ambiente. Utiliza-se o plano de trabalho e as necessidades visuais do usuário como referência. Embora avalie condições dinâmicas anuais, tal indicador não permite averiguar níveis excessivos e não prevê efeitos adversos associados ao desconforto visual e à sobrecarga térmica. A UDI, por sua vez, classifica níveis de iluminação quanto à frequência anual em que determinada faixa de iluminância incide sobre o plano de trabalho. As faixas de iluminância abaixo de 100 lux e acima de 3.000 lux são consideradas inapropriadas. Já os níveis de iluminação entre 300 lux e 3.000 lux são classificados como iluminância autônoma, portanto prescindindo de iluminação artificial, enquanto os níveis de iluminação entre 100 lux e 300 lux demandam suplementação, sendo classificados como iluminância suficiente (Tabela 1).

Os índices associados ao ofuscamento determinam o grau de desconforto visual causado por fontes de luz ou contrastes excessivos em um campo visual específico. O índice probabilidade de ofuscamento da luz natural (Daylight Glare Probability - DGP) é um método de predição da ocorrência de desconforto visual que adota como parâmetro a iluminância do plano vertical no campo de visão do observador (WIENOLD; CHRISTOFFERSON, 2006; WIENOLD, 2010). A escala de classificação, com valores acima de 0,45 e menores que 0,30 , corresponde a um percentual de $45 \%$ de pessoas em condições intoleráveis de ofuscamento e $30 \%$ em condições imperceptíveis respectivamente (JAKUBIEC; REINHART, 2010).

As métricas de desempenho da luz natural baseadas nos níveis de iluminação também possibilitam a avaliação do ofuscamento a partir da identificação das zonas excessivamente iluminadas, portanto com grandes chances de desconforto. Ainda que o limite superior tolerável para ambientes residenciais seja maior que os indicados em estudos em escritório, níveis de iluminação acima de 3.000 lux (eUDI>3.000 lux) podem provocar ofuscamento. Uma limitação na análise do ofuscamento através da identificação da iluminância excessiva é que o plano de análise da iluminância excessiva é horizontal, com altura média de $0,76 \mathrm{~m}$, enquanto o plano de análise do DGP é vertical, com altura equivalente a $1,20 \mathrm{~m}$ (nível dos olhos).

Tabela 1 - Níveis de iluminação para ambientes de escritórios

\begin{tabular}{l|c}
\hline \multicolumn{1}{c|}{ Classificação } & Faixa de iluminância \\
\hline Excessivo (inapropriado) - Exceeded - eUDI & $\mathrm{E} \geq 3.000$ lux \\
Autônomo - Autonomous - aUDI & $300 \leq \mathrm{E}<3.000$ lux \\
Suficiente, mas com necessidade de iluminação artificial - Supplemental - sUDI & $100 \leq \mathrm{E}<300$ lux \\
Insuficiente (inapropriado) - Fell short - $_{\mathrm{f}} \mathrm{UDI}$ & $\mathrm{E}<100$ lux \\
\hline
\end{tabular}

Fonte: Mardaljevik et al. (2011). 


\section{Método}

Os procedimentos adotados na presente pesquisa são apresentados em quatro itens:
(a) levantamento in loco;
(b) caracterização dos modelos;
(c) métrica dinâmica; e
(d) métodos de análise.

\section{Levantamento in loco}

O objeto de estudo é um recorte urbano de traçado recorrente no Brasil e inserido na zona bioclimática 8 , que compreende grande parte do país (ABNT, 2005). O universo da pesquisa foi delimitado em área de baixa latitude (latitude $7^{\circ} \mathrm{S}$ ), considerada uma das localidades mais verticalizadas do município de João Pessoa, PB. Em porção urbana central, o recorte apresenta 15 edifícios residenciais com mais de cinco pavimentos e demais lotes ocupados com edifícios térreos (Figura 1).

As principais características das edificações, especialmente o coeficiente de reflexão e o percentual de abertura na fachada (PAF), foram identificadas através de pesquisa documental e de levantamento in loco. A prefeitura local disponibilizou 25 projetos de edifícios datados pelo habite-se no período de 2000 a 2010 (Figura 2).

Para a caracterização do coeficiente médio de reflexão das superfícies verticais foram identificados materiais e cores das fachadas, e proporção e dimensões dos fechamentos opacos e transparentes. Com o auxílio de fotografias e do projeto legal, cada edifício foi digitalizado, e as áreas das superfícies do pavimento-tipo foram calculadas. Na Figura 3 há a fachada do projeto legal (a) e a fotografia (b) de um dos edifícios levantados para o cálculo do coeficiente de reflexão médio (CIBSE, 2001; LEAL, 2013).

$O$ percentual de abertura na fachada foi identificado através do pavimento-tipo e da orientação dos edifícios da amostra. A dimensão foi identificada para caracterizar a forma com maior frequência. Destacaram-se as seguintes faixas de largura e altura:

(a) entre $1,00 \mathrm{~m} \mathrm{e} 1,50 \mathrm{~m}$ por $1,00 \mathrm{~m} \mathrm{e} 1,50 \mathrm{~m}$ nas fachadas nordeste e sudeste;

(b) entre $0,50 \mathrm{~m} \mathrm{e} 1,00 \mathrm{~m}$ por $0,50 \mathrm{~m} \mathrm{e} 1,00 \mathrm{~m}$ na orientação sudoeste; $\mathrm{e}$

(c) entre $0,5 \mathrm{~m} \mathrm{e} 1,00 \mathrm{~m}$ por $1,00 \mathrm{~m}$ e $1,50 \mathrm{~m}$ na fachada noroeste.

\section{Caracterização dos modelos}

As variáveis analisadas nos cenários urbanos foram:

(a) três tipos de cenários urbanos (configurações de entorno);

(b) dois coeficientes de reflexão nas superfícies verticais do entorno; $\mathrm{e}$

(c) elementos de proteção solar horizontal nas edificações do entorno com três profundidades (Figura 4).

Adicionalmente, as seguintes variáveis foram analisadas nos ambientes internos:

(a) três alturas de pavimento; e

(b) quatro orientações.

Os modelos de cenário tiveram como base a planta cadastral do recorte urbano, que compreende nove quadras com predominância de uso residencial (Figura 5).

Os cenários urbanos foram classificados em:

(a) cenário atual (Modelo 1), equivalente à situação atual do recorte observada no levantamento, com suas principais características de gabarito, forma e percentual de aberturas na fachada;

(b) cenário isolado (Modelo 2), consistindo no edifício isolado; e

(c) cenário de máxima ocupação (Modelo 3), construído a partir do limite máximo de taxa de ocupação e do índice de aproveitamento (gabarito) permitido pela legislação local, tendo ainda como base o parcelamento atual do local (Figura 2).

O cenário de máxima ocupação (3) possui um desdobramento em relação ao coeficiente de reflexão das superfícies verticais:

(a) Modelo 3A, com coeficiente de reflexão de $58 \%$ (média obtida no levantamento in loco); e

(b) Modelo 3B, com coeficiente de reflexão de $90 \%$.

Tais dispositivos de proteção solar consistem em um plano horizontal, na altura da verga da abertura, adicionado aos pavimentos dos edifícios circunvizinhos, exceto o edifício de referência, e compreendendo quatro categorias, conforme a Figura 5:
(a) sem proteção (P0);
(b) $50 \mathrm{~cm}(\mathrm{P} 50)$;
(c) $100 \mathrm{~cm}(\mathrm{P} 100) ; \mathrm{e}$
(d) $150 \mathrm{~cm}(\mathrm{P} 150)$ 


\section{Figura 1 - Localização do recorte estudado}

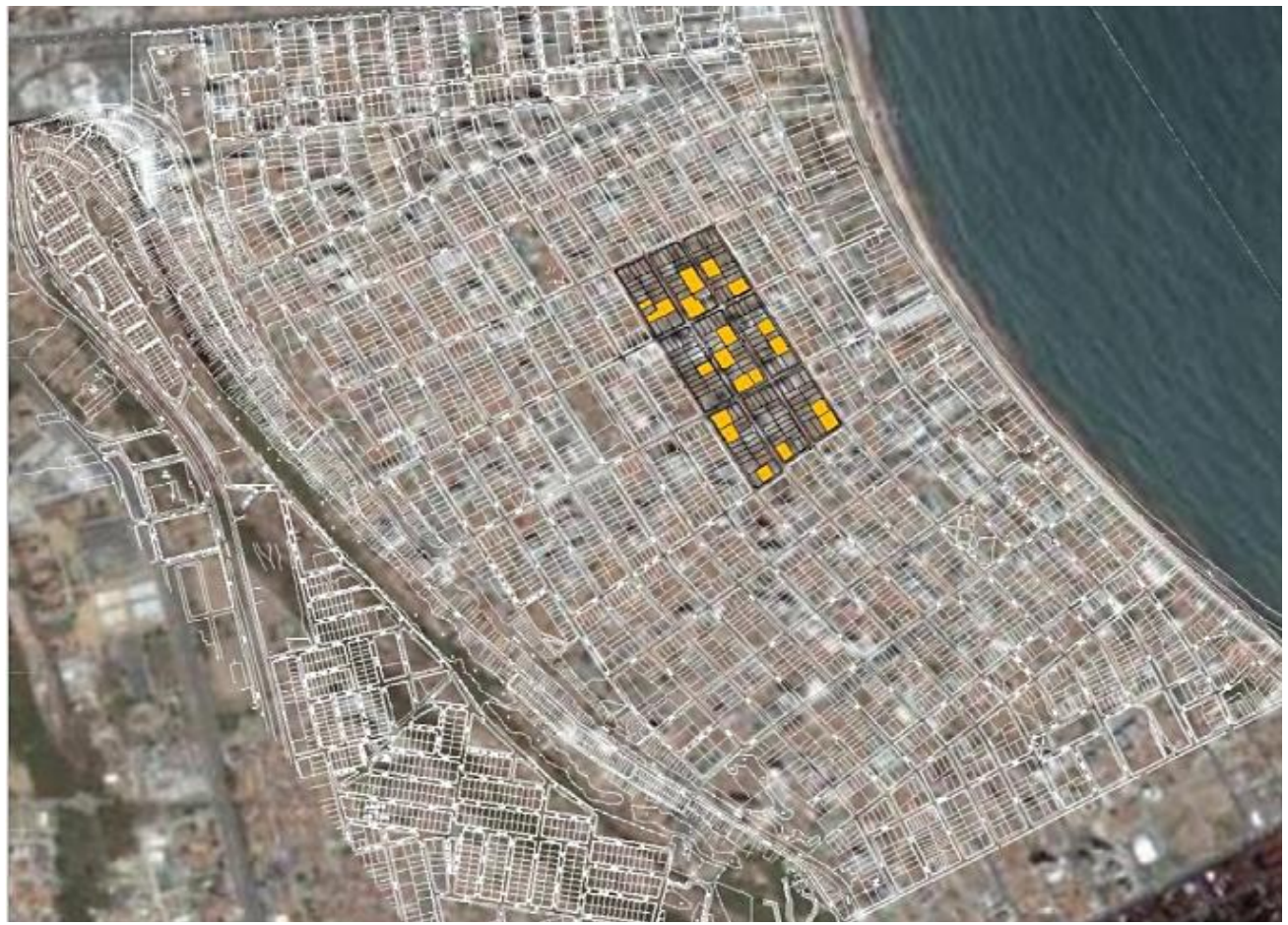

Fonte: adaptada do Googlemaps (2018).

Figura 2 - Amostra das edificações
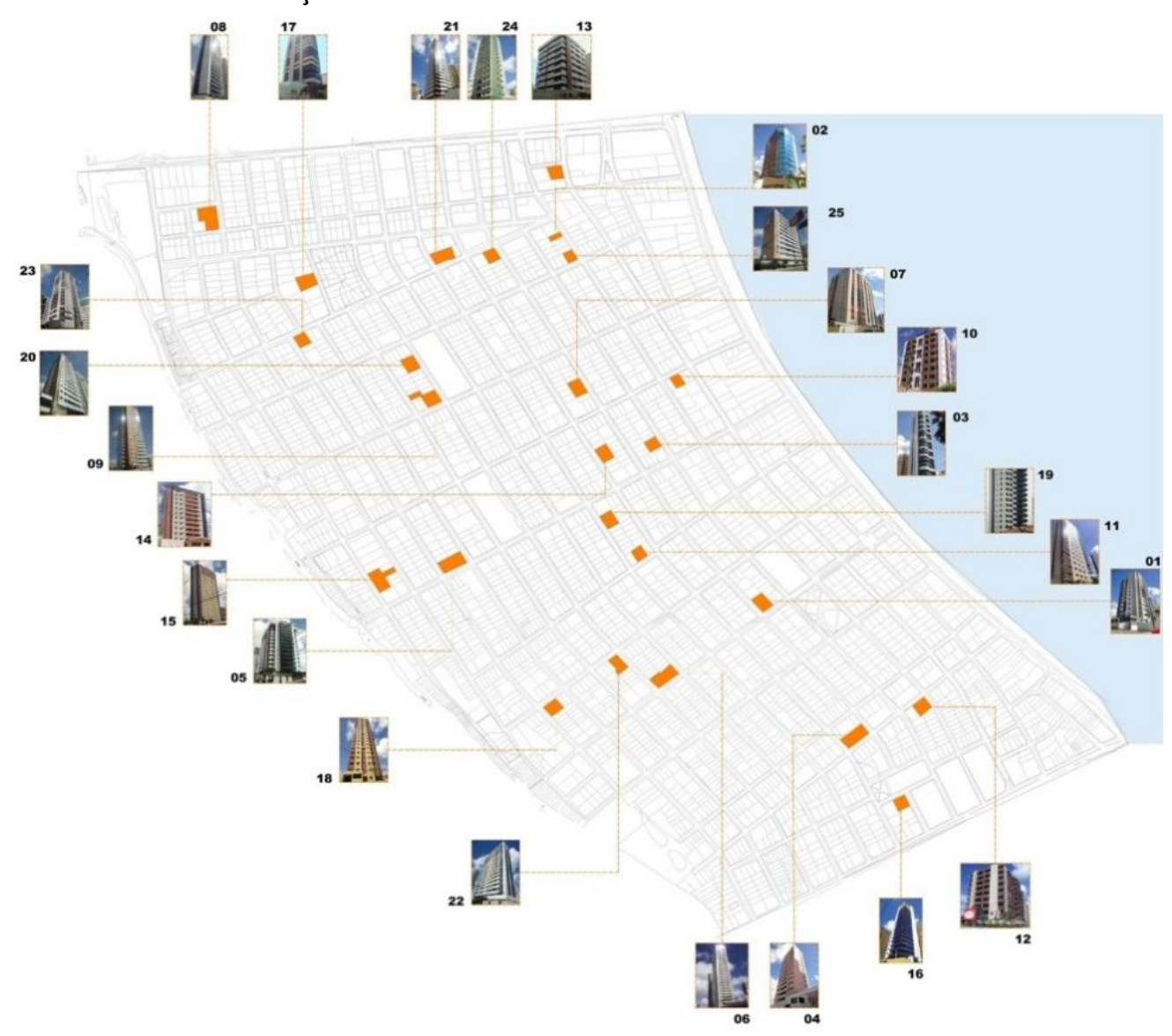

Fonte: adaptada d e Prefeitura Municipal de João Pessoa (2012). 
Figura 3 - Fachada (a) e fotografia (b) de um dos edifícios da amostra do levantamento do coeficiente de reflexão médio do entorno

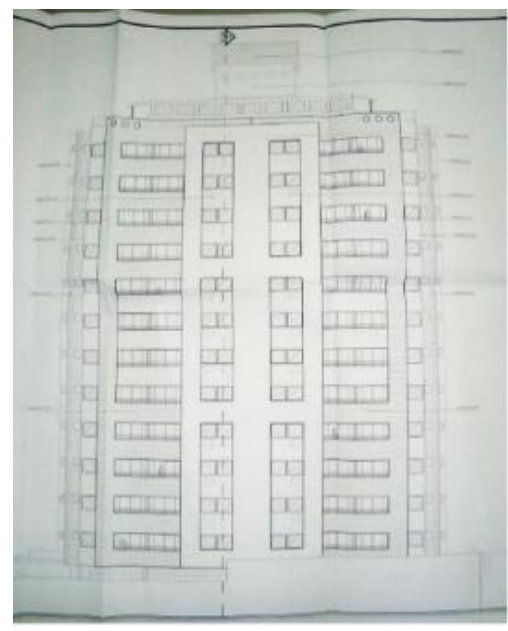

(a)

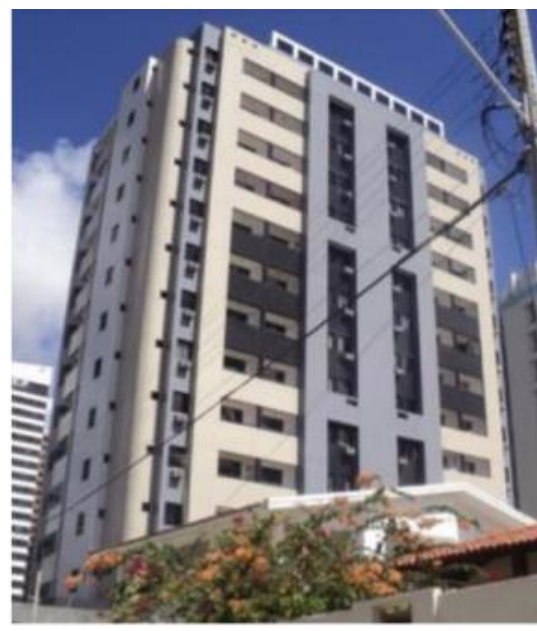

(b)

Figura 4 - (a) Sem proteção, (b) Proteção $50 \mathrm{~cm}$, (c) Proteção $100 \mathrm{~cm}$ (d) Proteção $150 \mathrm{~cm}$

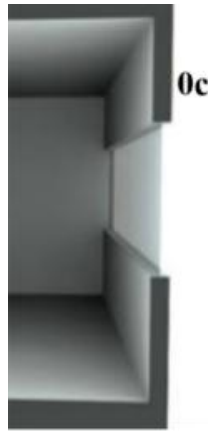

(a)

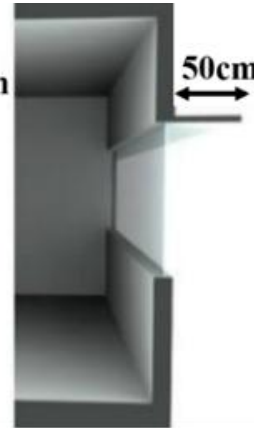

(b)

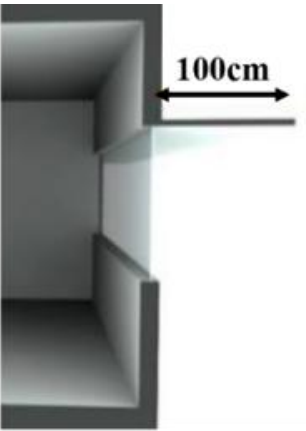

(c)

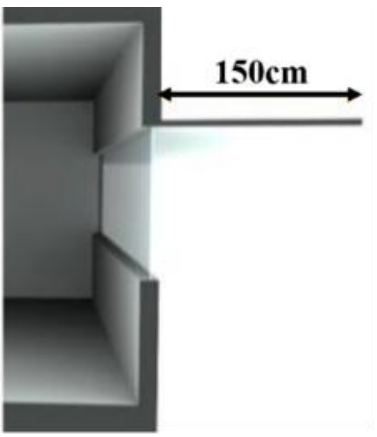

(d)

Figura 5- Cenário Atual - Modelo 1 (a); Cenário Isolado - Modelo 2 (b); e Cenário de Máxima Ocupação Modelo 3 (c)

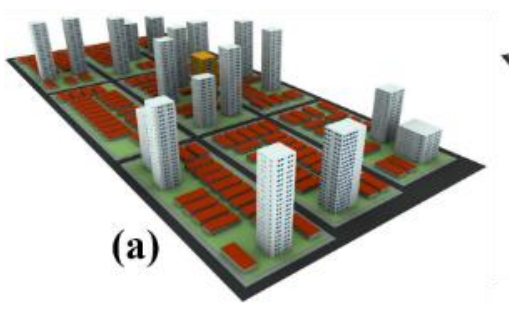

Comumente os estudos sobre elementos de proteção solar visam identificar os efeitos destes na iluminação do próprio edifício em que são instalados. O presente estudo, em outra direção, visa analisar os efeitos lumínicos dos elementos de proteção solar nos ambientes internos dos edifícios vizinhos. Elementos horizontais no entorno ampliam as superfícies de reflexão, o que influencia na iluminação do ambiente interno (CABÚS, 2004), assim como, ao aumentar o sombreamento das superfícies verticais, podem reduzir o potencial de ofuscamento.
Todos os cenários possuem um edifício de referência, com altura equivalente a 15 pavimentos (45 m), inserido em quadra e lote com posição central no recorte urbano (Figura 6a). Adotaram-se para o lote dimensões de $39 \mathrm{~m}$ x $30 \mathrm{~m}\left(1.170 \mathrm{~m}^{2}\right)$. Aplicando a regra do recuo progressivo presente na legislação local, obtêm-se os limites mínimos de afastamento e recuo: $8,5 \mathrm{~m}$ nas laterais e fundos, e 5,0 m no recuo frontal (Figura 6b). A refletividade adotada nas superfícies horizontais ao nível do solo foi de $18 \%$ nas ruas, $27 \%$ nas calçadas, recuos e afastamentos laterais, e $30 \%$ nos planos de cobertura.

102 LEAL, L. de Q.; LEDER, S. M. 
A lâmina do edifício é retangular, com dimensões de $16,5 \mathrm{~m}$ x $22 \mathrm{~m}$, e cada pavimento composto de quatro unidades habitacionais de $80 \mathrm{~m}^{2}$, com core de $25 \mathrm{~m}^{2}$. O ambiente interno de análise possui dimensões de $5,50 \mathrm{~m}$ de comprimento e $6,5 \mathrm{~m}$ de profundidade $\left(35,75 \mathrm{~m}^{2}\right)$, compatíveis com a indicação para que ambientes sem proteção solar sejam iluminados naturalmente a um alcance de até 2,5 vezes a altura da verga (REINHART, 2005). A abertura, disposta em toda a extensão do ambiente e sem elemento de proteção solar, mede $5,50 \mathrm{~m}$ de comprimento e 1,20 $\mathrm{m}$ de altura, e verga a 2,20 $\mathrm{m}$ do piso (Figura 7).

Os ambientes internos foram dispostos seguindo a orientação predominante do recorte urbano sudoeste (lateral), sudeste (fundos), nordeste (frente) e noroeste (lateral) -, conforme Figura 6c. Para a análise da variável altura do pavimento foram selecionados três níveis: térreo $(\mathrm{T}:+0,50 \mathrm{~m})$, intermediário (I: $7^{\circ}$ andar, $+21,50 \mathrm{~m}$ ) e cobertura (C: $15^{\circ}$ andar, $+42,00 \mathrm{~m}$ ). Quanto aos coeficientes de reflexão internos, parede, piso e teto possuem $58 \%, 30 \%$ e $84 \%$ respectivamente. O coeficiente de transmissão do vidro é de $90 \%$, e a reflexão de $6,7 \%$ (REINHART, 2010). O coeficiente de reflexão das superfícies externas do edifício em estudo foi mantido constante em todos os cenários, com $90 \%$.

\section{Métricas dinâmicas}

Para o desenvolvimento da pesquisa foi utilizado como ferramenta de simulação o programa
Daysim. Validado pelo National Research Council Canada (NRCC), o software utiliza os algoritmos do Radiance para realização de estudos dinâmicos da luz natural. Os dados de saída correspondem ao desempenho anual em níveis de iluminação dos ambientes, atendendo às condições reais de disponibilidade de luz com base no Typical Reference Year (TRY). Nesse sentido, utilizou-se o arquivo climático TRY específico da cidade em estudo (litorânea e de baixa latitude) com extensão do Energy Plus Weather (.epw), a partir de registros do Inmet correspondentes ao ano típico de 2008. O comportamento da luz natural é simulado por meio do mecanismo raio traçado (raytracing), de onde são extraídos dados de saída de iluminância com o Daylight Coefficients (.dc), do Annual Illuminance Profile (.ill) e de ofuscamento com o Daylight Glare Probability (.dgp).

As combinações das variáveis de entorno, descritas na seção Caracterização dos modelos, resultaram em 120 simulações, sendo 24 modelos destinados ao Modelo 1 e 2, com variação de orientação e pavimento, e 96 ao Modelo 3, com variação de orientação, pavimento e dispositivo de proteção solar nas fachadas vizinhas (Figura 6). Os modelos foram utilizados para análise de desempenho da luz natural e da ocorrência de ofuscamento, totalizando 240 simulações.

Figura 6 - Recorte urbano (a), lote e edifício de referência (b) e ambientes avaliados por pavimento (c)

\section{LEGENDA \\ RECUO \\ EDIFÍCIO REFERÊNCIA \\ AMBIENTE EM ANÁLISE}

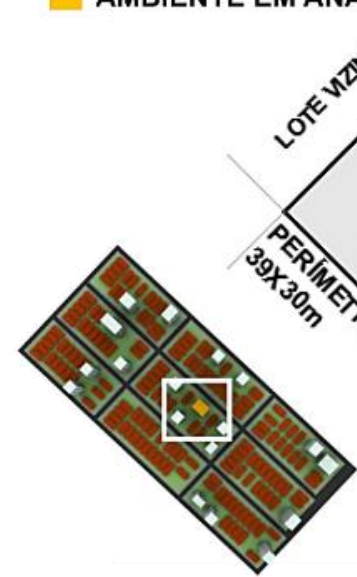

(a)

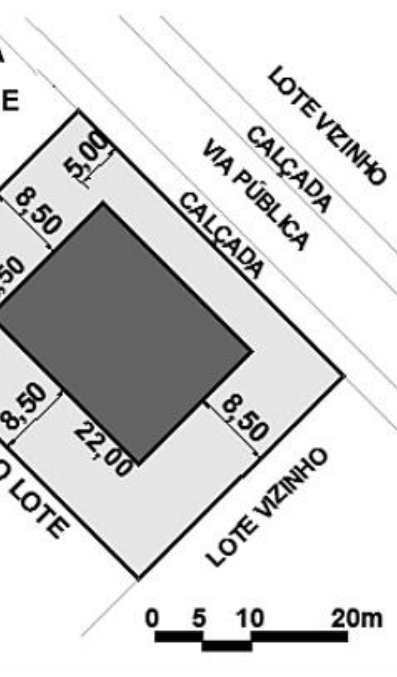

(b)

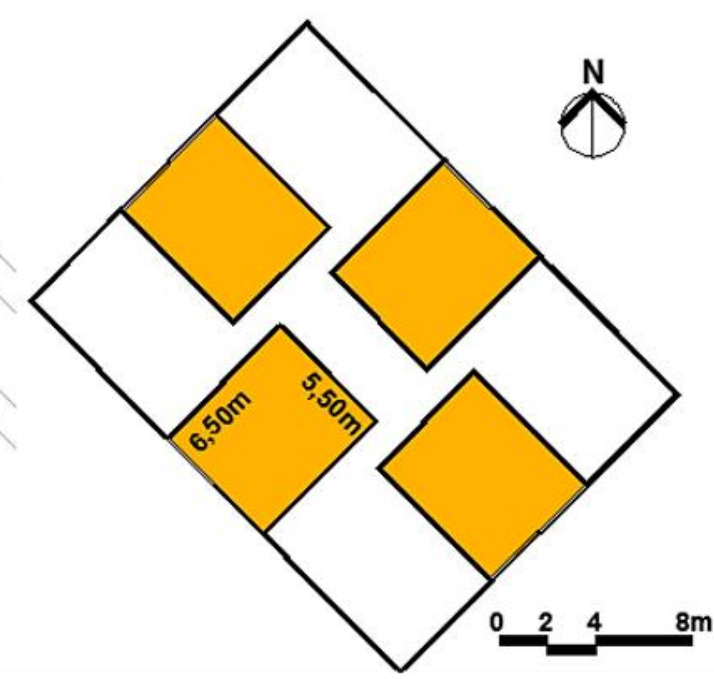

(c) 
Figura 7 - (a) Vista de topo e (b) vista lateral do modelo de ambiente interno
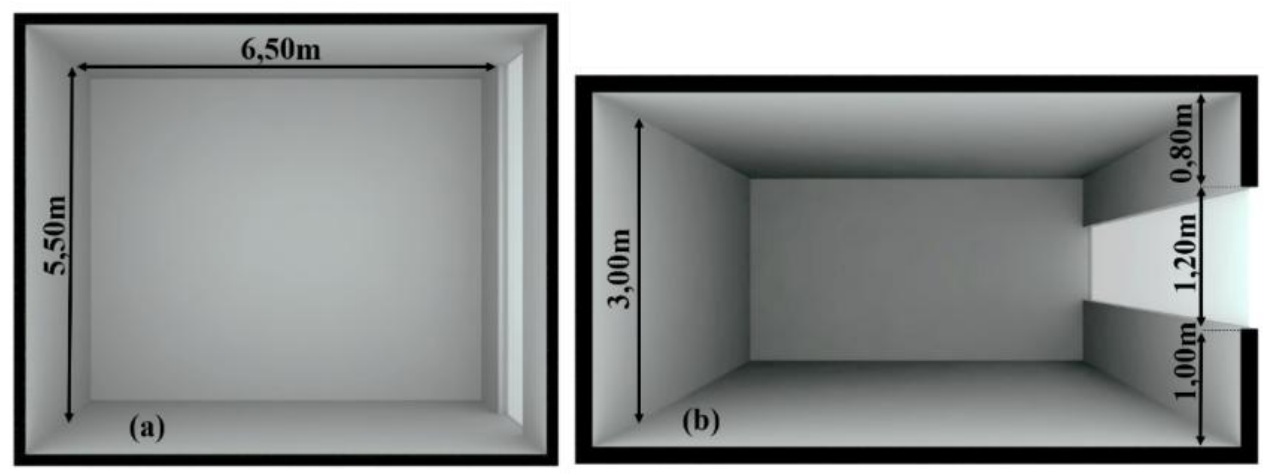

A avaliação do desempenho foi efetuada por meio de malha de pontos, direcionados para cima, distribuída em quadrantes de $1,10 \mathrm{~m}$ x 1,08 m, totalizando 30 pontos equidistantes, a $0,55 \mathrm{~m}$ da parede, disposta em plano de trabalho intermediário a $0,85 \mathrm{~m}$ do piso. Como o ambiente não tem uso específico, optou-se por uma medida intermediária que representasse a média de planos de trabalho presentes em ambientes residenciais cozinha, banheiro, sala (Figura 8). Todas as simulações foram realizadas no horário das $6 \mathrm{~h}$ às $17 \mathrm{~h}$, em intervalos de $60 \mathrm{~min}$, durante todo o ano, com padrão de ocupação contínuo, sem intervalos.

$\mathrm{Na}$ avaliação da probabilidade de ofuscamento da luz natural (Daylight Glare Probability - DGP), foi utilizado o programa Evalglare (a partir de arquivos de pontos de visão - view file). Quatro pontos de simulação foram locados equidistantes a $1,60 \mathrm{~m}$, alinhados perpendicularmente ao eixo central da janela $(2,75 \mathrm{~m})$, a $0,80 \mathrm{~m}$ da abertura e da parede posterior com altura do plano de visão a $1,20 \mathrm{~m}$ do piso, representando níveis de visão do observador direcionados à abertura (Figura 9). Foi adotado o mesmo padrão de ocupação das métricas anteriores, o que reduziu o período de 1 ano para 4 meses, definidos para caracterizar as estações do ano (março, junho, setembro e dezembro).

\section{Método de análise}

Os critérios de avaliação da iluminação utilizados foram Autonomous Useful Daylight Illuminance (aUDI300-3000lux) e Exceeded Useful Daylight Illuminance (eUDI>3000lux), conforme a Tabela 2. A iluminância natural útil autônoma (aUDI3003000lux) avalia o percentual anual em que o ponto atinge níveis de iluminação na faixa entre 300 lux e 3.000 lux, tendo como parâmetro mínimo $50 \%$ de área de piso acima de $75 \%$ do ano, considerando exclusivamente que os usuários não são ativos e dispensando-se fontes artificiais. Já a iluminância excessiva (eUDI>3000lux) avalia áreas muito iluminadas superiores a $5 \%$ de horas ocupadas no ano. Esse percentual determina a qualidade lumínica do espaço quanto ao grau de uniformidade, a presença da luz solar direta e as condições visuais, como a possível ocorrência de ofuscamento (NABIL; MARDALJEVIC, 2005; ROGERS, 2006; MARDALJEVIC et al., 2012).

Inicialmente foi investigado o percentual de área iluminada acima de $75 \%$ com iluminância autônoma (aUDI) através de gráficos com a distribuição dos dados em caixa (boxplot), aplicando na sequência testes estatísticos de normalidade com valor $-\mathrm{p} \geq 5$ (teste de Shapiro) e de variância (teste qui-quadrado). De acordo com o resultado da distribuição confirmada com o teste de normalidade, fez-se a escolha do teste de hipóteses, sendo o teste T de Student (paramétrico) ou o Wilcoxon Rank(não paramétrico). Com estes se pode verificar chances de semelhanças ou diferenças entre o comportamento das amostras, estimando margens de erro com limites superior e inferior a $5 \%$ do valor esperado (intervalos de confiança de 95\%). Esses resultados foram obtidos por meio de métodos estatísticos com o uso do software R versão 3.0.1.

Pela avaliação da iluminância excessiva (eUDI), foi analisada apenas a contribuição da obstrução do entorno (fachadas), especialmente no pavimento intermediário (Figura 10). Assim, a cobertura, que recebe menor reflexão dos elementos verticais de entorno, e o pavimento térreo, de iluminância pouco expressiva, não foram incluídos nesta análise. 
Figura 8 - (a) Pontos de simulação - iluminância e (b) plano de trabalho - fachada sudoeste

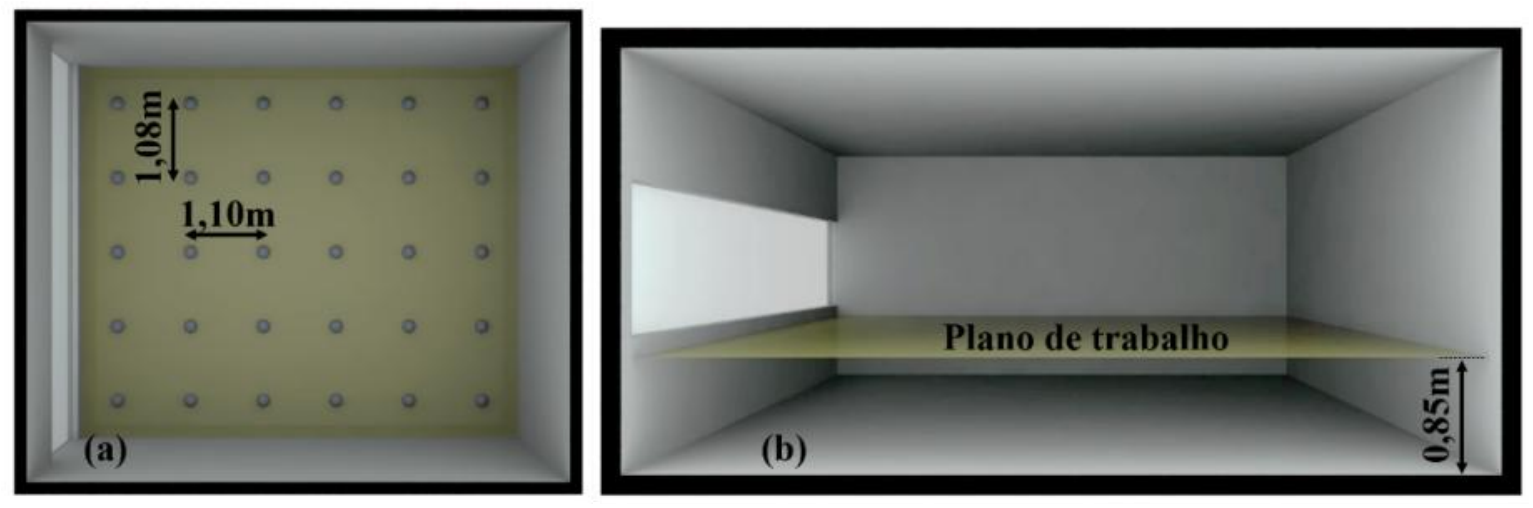

Figura 9 - Pontos de simulação - Ofuscamento em planta (a) e plano de visão do observador (b)
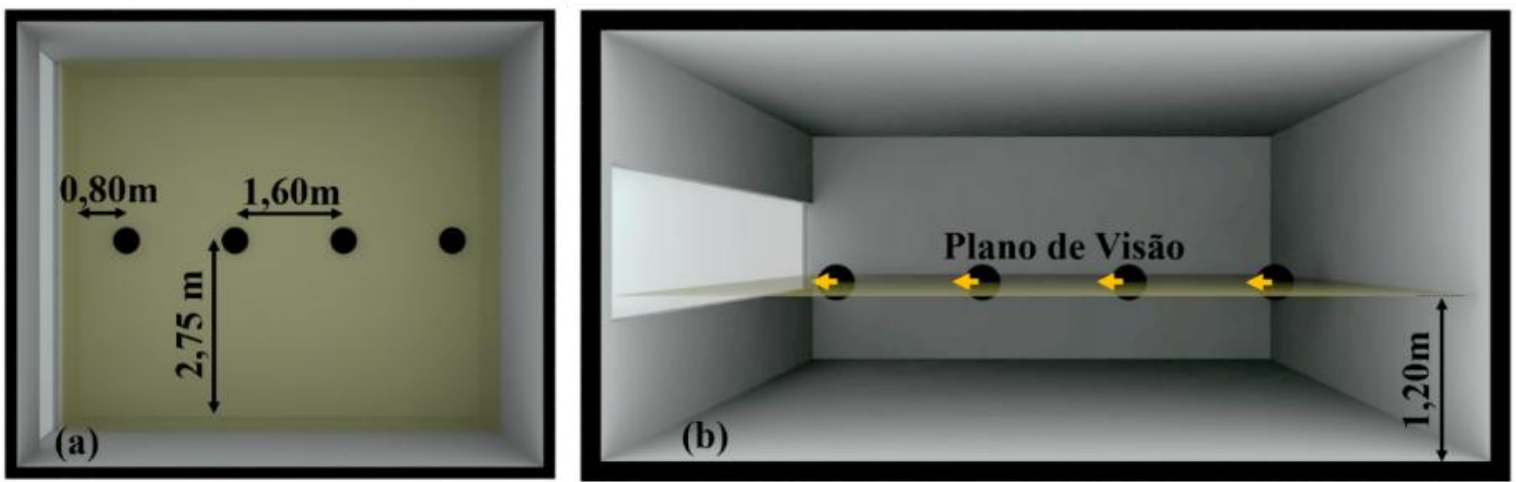

Tabela 2 - Faixas de predição de iluminação natural

\begin{tabular}{l|c|c}
\hline \multicolumn{1}{c|}{ Classificação } & Iluminância Natural Útil (UDI) & Parâmetros de análise \\
\hline Autônomo - aUDI & $300 \leq \mathrm{E}<3.000$ lux & Área iluminada $>50 \%$ com aUDI $>75 \%$ \\
Excessivo - eUDI & $\mathrm{E} \geq 3.000$ lux & Zonas com eUDI $>5 \%$ \\
\hline
\end{tabular}

Figura 10 - (a) Corte: entorno e ambiente referência e (b) comportamento da eUDI em corte

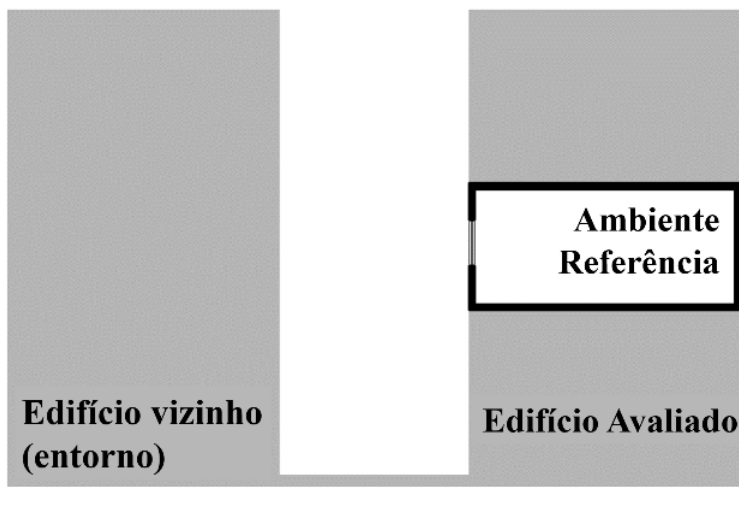

(a)

Para avaliação da probabilidade de ofuscamento da luz natural (Daylight Glare Probability - DGP), as diferenças na ocorrência de desconforto visual foram identificadas inicialmente com os gráficos de caixa, associadas ao teste qui-quadrado de

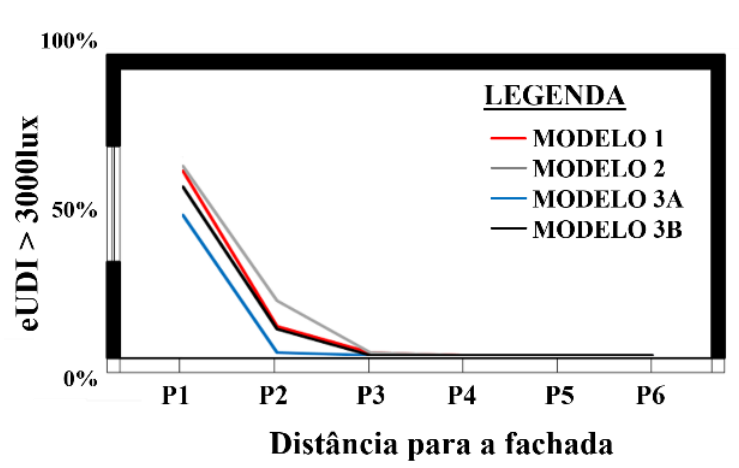

(b)

Pearsonpara verificar o grau de associação entre variáveis. Na sequência, aplicou-se o método estatístico da classe dos modelos lineares generalizados (MLG), com a regressão logística múltipla, baseada na predição de valores de 
variável resposta com valores de variáveis explicativas, averiguando-se os efeitos entre elas (JOHNSON; WICHERN, 2007).

Com o uso do modelo logístico, a análise de regressão de variáveis dicotômicas permitiu produzir modelo de predição de índices de ofuscamento $(\mathrm{Y})$ - variável resposta -, tomados por uma variável categórica binária a partir das variáveis explicativas $(\mathrm{X})$ : cenário/grau de obstrução, dispositivo de proteção, orientação e pavimento. Para tanto, tomaram-se como resposta apenas duas condições entre $0,35>\mathrm{DGP} \geq 0,45$ (WIENOLD; CHRISTOFFERSON, 2006). Esse critério foi adotado porque se fez necessária a escolha de faixas de predição referentes à ocorrência ou não do evento (Tabela 3 ).

O modelo de regressão logística múltipla é obtido através do logaritmo natural da razão da chance, expresso pela Equação 1.

$\ln \left(\frac{p \text { (sucesso })}{1-p(\text { sucesso })}\right) \beta_{o}+\beta_{1} \cdot X_{1}+\cdots+\beta_{n} \cdot X_{n} \quad$ Eq. 1

Razão da chance $=\left(\frac{p \text { (sucesso })}{1-p \text { (sucesso })}\right)=$

$e^{(\beta 0+\beta 1 . X 1+\cdots+\beta n \cdot X n)}$

Sendo:

$\beta=$ Coeficiente constante;

$\beta_{1} \cdot X_{1}=$ Coeficiente e variável $\mathrm{X}$; e

$\beta_{n} . X_{n}=$ Coeficiente e variável $\mathrm{n}$.

Por meio dela se estimaram os coeficientes com o método da máxima verossimilhança. Nesta etapa foi determinado o nível de relação existente entre os coeficientes das variáveis independentes e a variável dependente, denominada teste quiquadrado (Chi-Square) da razão de verossimilhança. $\mathrm{O}$ impacto da mudança das variáveis independentes foi verificado em cada coeficiente sobre a chance de ocorrer ofuscamento (Equação 2). Definida como medida de associação, a razão da chance (Odds chance) expressou a aproximação do quanto é mais provável $-p$ (sucesso) - ou improvável - 1-p (sucesso) ocorrer o evento, o que permitiu relacionar variáveis do estudo com o desconforto visual.

\section{Resultados}

Os principais resultados estão apresentados nos itens:

(a) percentual de área iluminada -iluminância natural autônoma;

(b) iluminância natural excessiva; e (c) probabilidade de ofuscamento da luz natural.

\section{Percentual de área iluminada: iluminância natural autônoma}

Com a aplicação do teste estatístico de normalidade (teste de Shapiro) e da análise de variância, foram rejeitados os pressupostos da distribuição normal e da variância constante, optando pelo teste não paramétrico Wilcoxon Rank. As comparações múltiplas rejeitaram a hipótese de igualdade dos níveis de iluminação entre os modelos, avaliando o comportamento dos cenários quanto à iluminação na faixa útil autônoma - aUDI>75\% do ano (Figura 11).

A mudança de cenário culminou em alterações expressivas dos percentuais de área iluminada. Os ambientes do Modelo 2 (cenário isolado) atingiram áreas de aUDI entre $50 \%$ e $80 \%$. Logicamente, os ambientes com menores percentuais sofreram influência das obstruções, sobretudo nos cenários de máxima ocupação com coeficiente de reflexão média (Modelo 3A). O sombreamento gerado pelas proteções horizontais nos edifícios vizinhos nos Modelos 3A e 3B contribuiu para alterações nos níveis de iluminação, observando-se crescimento gradativo da iluminância útil proporcional às dimensões dos dispositivos, com ênfase para a proteção de 1,50 m (P150).

Comparando os ambientes do Modelo 1 (cenário atual) e do Modelo 2 (cenário isolado), observa-se o aumento da iluminação autônoma em 10,2\%, o que caracteriza a magnitude do impacto do entorno edificado na redução dos níveis lumínicos. O Modelo 3 sofreu redução nos percentuais de iluminação em $21,5 \%$ e $13 \%$ nos ambientes com reflexão média no entorno (Modelo 3A) e máxima (Modelo 3B) respectivamente quando comparado com o Modelo 1. Quanto à refletividade das fachadas do entorno, o coeficiente máximo (Modelo 3B) aumenta a área iluminada dos ambientes em 8,5\%. Tanto o grau de obstrução como a ação da componente refletida externa contribuem para alterações no desempenho da iluminação dos ambientes internos (Tabela 4).

Os testes de hipóteses também confirmaram a influência da inserção dos elementos de proteção solar horizontal nos edifícios do entorno. No Modelo 3A a ação desses dispositivos registra acréscimos de 3,6\%, 10,5\% e 19,91\% nas estimativas das áreas iluminadas com dimensão $0,50 \mathrm{~m}, 1,00 \mathrm{~m}$ e $1,50 \mathrm{~m}$ respectivamente. Esse aumento pode ser atribuído ao incremento de superfícies horizontais no entorno (Tabela 5). 
Tabela 3 - Faixas de predição de ofuscamento - DGP

\begin{tabular}{l|c|c|c|c}
\hline & Imperceptível & Perceptível & Desconfortável & Intolerável \\
\hline DGP & $<0,35$ & $0,35-0,40$ & $0,40-0,45$ & $\geq 0,45$ \\
\hline DGP ADOTADO & $<0,35$ & $\geq 0,45$ & & \\
\hline CONDIÇÃO & Não ocorre ofuscamento $(\mathrm{Y}=0)$ & \multicolumn{2}{|c}{ Ocorre ofuscamento(Y=1) } \\
\hline
\end{tabular}

Fonte: adaptada de Wienold e Christofferson (2006).

Figura 11 - Percentual de área do ambiente iluminada por cenário e por tamanho de proteção
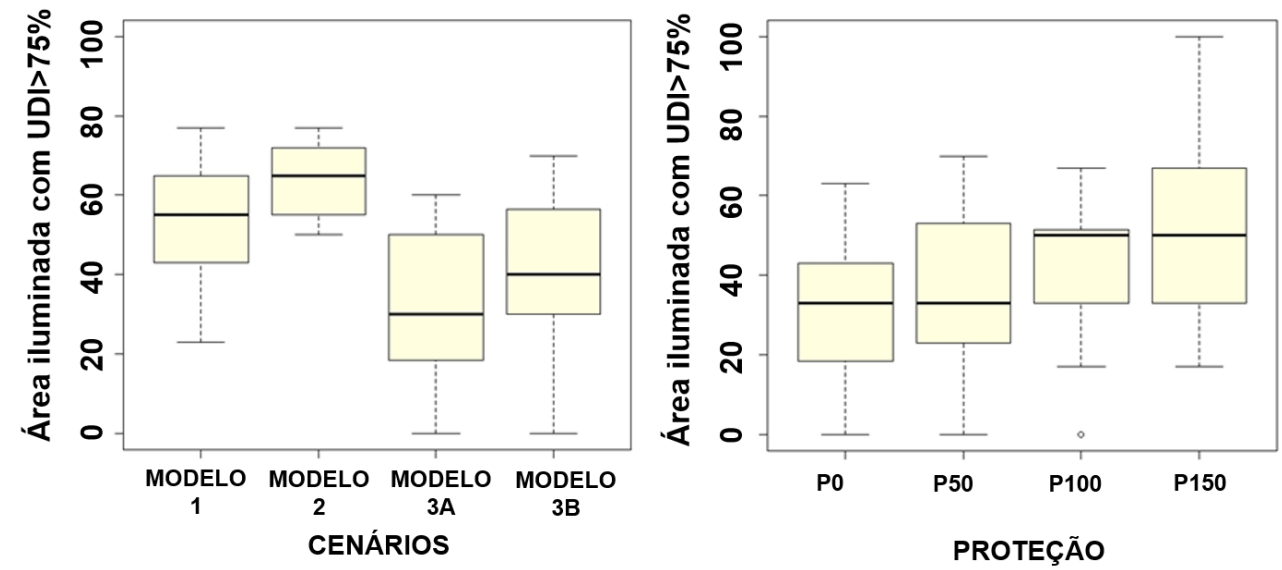

MODELO 1 - Cenário Atual

MODELO 2 - Cenário Isolado

MODELO 3A - Cenário com ocupação máxima e refletância média

MODELO 3B - Cenário com ocupação máxima e refletância $90 \%$

PO - Fachadas do entorno sem proteção

P50 - Fachadas do entorno com proteção $50 \mathrm{~cm}$

P100 - Fachadas do entorno com proteção $100 \mathrm{~cm}$

P150 - Fachadas do entorno com proteção $150 \mathrm{~cm}$

Tabela 4 - Comparativo entre a área iluminada referente aos cenários

\begin{tabular}{l|l}
\hline \multicolumn{1}{c|}{ Cenário } & \multicolumn{1}{c}{ Resultado do teste - Estimativa } \\
\hline Modelo 1 x Modelo 2 & Modelo 1 < Modelo 2 - Diferença em 10,2\%* \\
Modelo 1 x Modelo 3A & Modelo 1 > Modelo 3A - Diferença em 21,5\%* \\
Modelo 1 x Modelo 3B & Modelo 1 > Modelo 3B - Diferença em 13\%* \\
Modelo 3A x Modelo 3B & Modelo 3A < Modelo 3B - Diferença em 8,5\%* \\
\hline
\end{tabular}

Nota: Legenda:

Modelo 1 - Cenário atual;

Modelo 2 - Cenário isolado;

Modelo 3A - Cenário com ocupação máxima e refletância média;

Modelo 3B - Cenário com ocupação máxima e refletância 90\%; e

*Hipótese de igualdade rejeitada e estimativa da diferença com margem de erro de $5 \%$.

Tabela 5 - Comparativo entre área iluminada referente às proteções e coeficiente de reflexão média

\begin{tabular}{l|c}
\hline \multicolumn{1}{c|}{ Proteção } & Resultado do teste - Estimativa \\
\hline P0 X P50 & P0 < P50 - Diferença em 3,6\%* \\
P0 X P100 & P0 < P100 - Diferença em 10,5\%* \\
P0 X P150 & P0 < P150 - Diferença em 19,9\%* \\
\hline
\end{tabular}

Nota: Legenda:

PO - Sem proteção;

P50 - Proteção externa $50 \mathrm{~cm}$;

P100 - Proteção externa $100 \mathrm{~cm}$;

P150 - Proteção externa $150 \mathrm{~cm}$; e

*Hipótese de igualdade rejeitada e estimativa da diferença com margem de erro de $5 \%$.

A Figura 12 ilustra diferenças perceptíveis entre os percentuais de área iluminada dos ambientes nos quatro cenários em função das três alturas dos pavimentos. No pavimento térreo o impacto da obstrução do entorno nos ambientes internos é maior (com exceção dos inseridos no cenário isolado - Modelo 2). Em relação aos pavimentos mais altos (intermediário e cobertura), eles apresentam redução de $15 \%$ e $40 \%$ de área iluminada respectivamente. 
Figura 12 - Percentual de área iluminada dos pavimentos por cenário
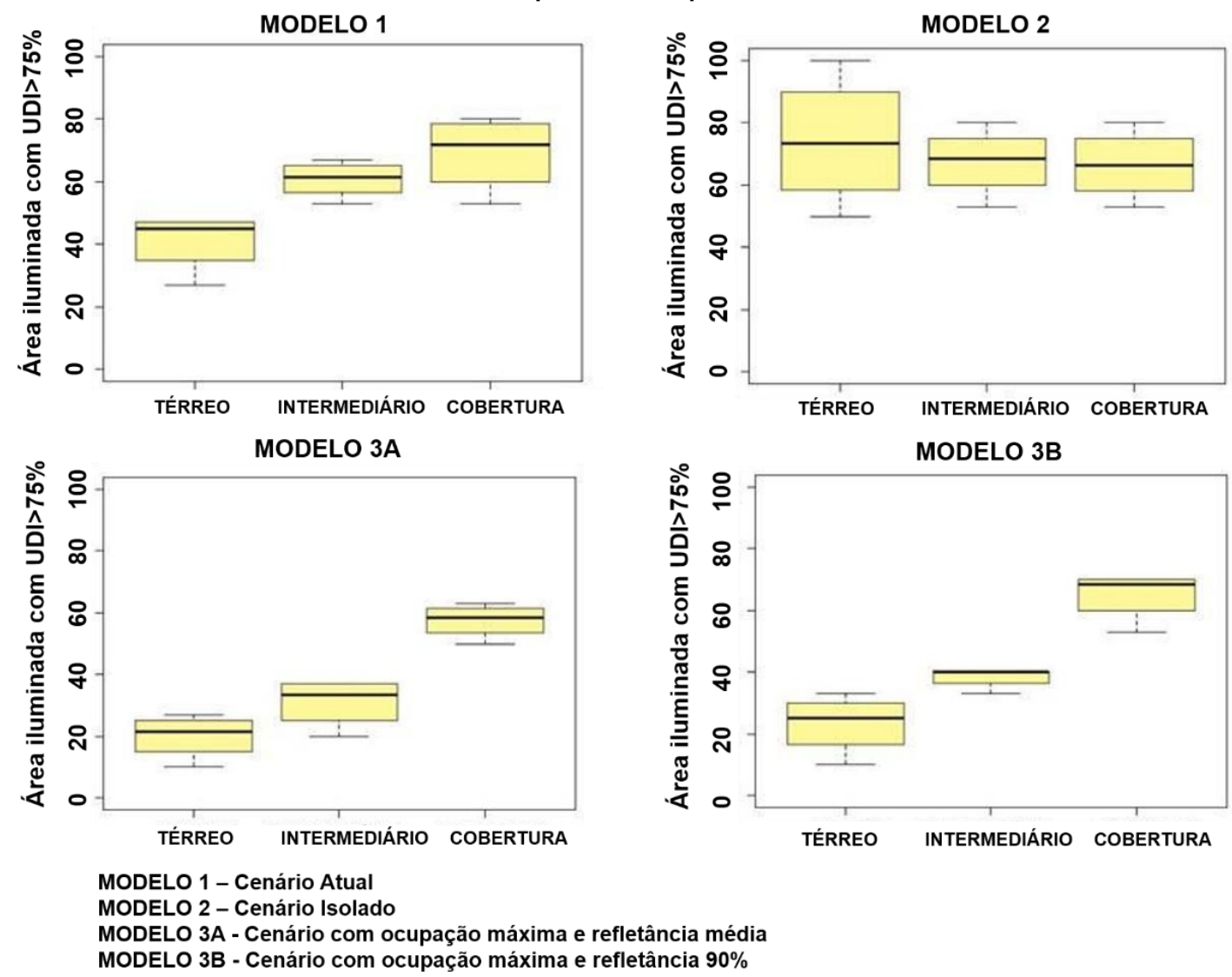

Os valores obtidos com as análises estatísticas confirmam as observações feitas com base nos gráficos boxplot. $\mathrm{Na}$ Tabela 6 observa-se o comparativo dos níveis de iluminação entre os cenários em estudo. As maiores diferenças estão concentradas no pavimento térreo do cenário atual (Modelo 1), com redução de 33,2\% nos níveis de iluminação quando comparado com o cenário isolado (Modelo 2).

O aumento da refletividade das fachadas do entorno, de $58 \%$ para $90 \%$, acrescenta $3 \%$ e $7 \%$ na iluminação do pavimento térreo e do intermediário respectivamente. $\mathrm{Na}$ cobertura os níveis de iluminação nos ambientes dos Modelos 1, 2 e 3B não apresentam diferenças estatisticamente significativas, com exceção do cenário com fachadas de refletividade média (58\%).

Quanto à orientação, as diferenças entre os ambientes nos Modelos 1 e 2 são irrelevantes, o que aponta maiores percentuais de iluminação nas fachadas noroeste e sudeste. Comportamento similar a tais cenários ocorre nas orientações sudeste, noroeste e nordeste no Modelo 3B. Os ambientes da fachada sudeste no Modelo 3A também foram evidentes. Em todos os cenários os ambientes localizados na fachada orientada para sudoeste registraram os menores níveis de iluminação (Figura 13).

O comparativo entre ambientes de mesma orientação e de cenários distintos destaca pequenas diferenças nos Modelos 1 e 2. Para esses cenários a orientação sudoeste apresentou grande chance de igualdade, com margem de erro de $\pm 5 \%$. No entanto, os Modelos 3A e 3B apresentam diferenças significativas, especialmente nas orientações sudoeste e sudeste em relação ao Modelo 3B e nas orientações noroeste e nordeste em relação ao Modelo 3A (Tabela 7). 
Tabela 6 - Comparativo dos pavimentos entre cenários

\begin{tabular}{l|c}
\hline \multicolumn{1}{c|}{ Pavimento térreo } & \multicolumn{1}{c}{ Resultado do teste - Estimativa } \\
\hline Modelo $1 \times$ x Modelo 2 & Modelo 1 < Modelo 2 - Diferença estimada em 33,2\%* \\
Modelo 1 x Modelo 3A & Modelo 1 > Modelo 3A - Diferença estimada em 20\%* \\
Modelo 1 x Modelo 3B & Modelo 1 > Modelo 3B - Diferença estimada em 17\%* \\
\hline Pavimento intermediário & \multicolumn{1}{c}{ Resultado do teste - Estimativa } \\
\hline Modelo 1 x Modelo 2 & Modelo 1 < Modelo 2 - Diferença estimada em 9,5\%* \\
Modelo 1 x Modelo 3A & Modelo 1 > Modelo 3A - Diferença estimada em 29,7\%* \\
Modelo 1 x Modelo 3B & Modelo 1 > Modelo 3B - Diferença estimada em 22,5\%* \\
\hline \multicolumn{1}{c}{ Pavimento cobertura } & \multicolumn{1}{c}{ Resultado do teste - Estimativa } \\
\hline Modelo 1 x Modelo 2 & Modelo 1 = Modelo 2** \\
Modelo 1 x Modelo 3A & Modelo 1 > Modelo 3A - Diferença em 11,7\%* \\
Modelo 1 x Modelo 3B & Modelo 1 = Modelo 3B** \\
\hline
\end{tabular}

Nota: Legenda:

Modelo 1 - Cenário atual;

Modelo 2 - Cenário isolado;

Modelo 3A - Cenário com ocupação máxima e refletância média; e

Modelo 3B - Cenário com ocupação máxima e refletância $90 \%$.

*Hipótese de igualdade rejeitada e estimativa da diferença com margem de erro de $5 \%$.

**Hipótese de igualdade confirmada, de acordo com o teste de hipóteses Wilcoxon Rank.

Figura 13 - Percentual de área iluminada $x$ orientação
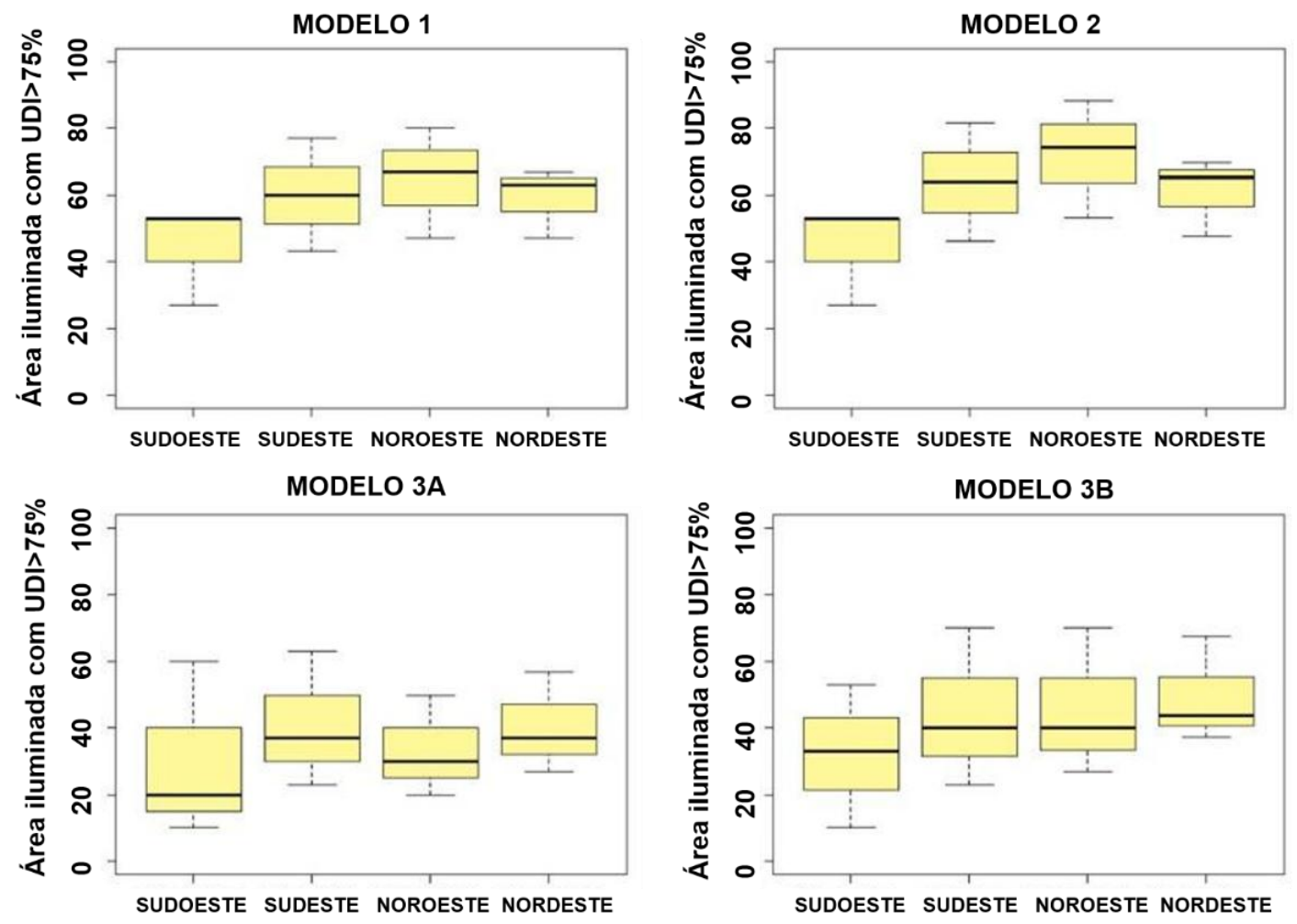

MODELO 1 - Cenário Atual

MODELO 2 - Cenário Isolado

MODELO 3A - Cenário de entorno com ocupação máxima e refletância média

MODELO 3B - Cenário de entorno com ocupação máxima e refletância $90 \%$ 
Tabela 7 - Comparativo da orientação por cenário

\begin{tabular}{c|c}
\hline Orientação sudoeste & Resultado do teste - Estimativa \\
\hline Modelo 1 x Modelo 2 & Modelo 1 = Modelo 2** \\
Modelo 1 x Modelo 3A & Modelo 1 > Modelo 3A - Diferença estimada em 15\%* \\
Modelo 1 x Modelo 3B & Modelo 1 > Modelo 3B - Diferença estimada em 18,5\%* \\
\hline Orientação sudeste & \multicolumn{1}{c}{ Resultado do teste - Estimativa } \\
\hline Modelo 1 x Modelo 2 & Modelo 1 < Modelo 2 - Diferença estimada em 3\%* \\
Modelo 1 x Modelo 3A & Modelo 1 > Modelo 3A - Diferença estimada em 13\%* \\
Modelo 1 x Modelo 3B & Modelo 1 > Modelo 3B - Diferença estimada em 19\%* \\
\hline Orientação noroeste & \multicolumn{1}{c}{ Resultado do teste - Estimativa } \\
\hline Modelo 1 x Modelo 2 & Modelo 1 < Modelo 2 - Diferença estimada em 8,5\%* \\
Modelo 1 x Modelo 3A & Modelo 1 > Modelo 3A - Diferença estimada em 19,25\%* \\
Modelo 1 x Modelo 3B & Modelo 1 > Modelo 3B - Diferença estimada em 14,6\%* \\
\hline Orientação nordeste & \multicolumn{1}{c}{ Resultado do teste - Estimativa } \\
\hline Modelo 1 x Modelo 2 & Modelo 1 < Modelo 2 - Diferença estimada em 5,97\%* \\
Modelo 1 x Modelo 3A & Modelo 1 > Modelo 3A - Diferença estimada em 19\%* \\
Modelo 1 x Modelo 3B & Modelo 1 > Modelo 3B - Diferença estimada em 16,5\%* \\
\hline &
\end{tabular}

\section{Iluminância Natural Excessiva (eUDI)}

A definição da zona de iluminação excessiva foi investigada em função das iluminâncias acima de 3.000 lux no plano de trabalho. Os diagramas em seção vertical (corte) mostram a porção dos ambientes com eUDI>3000lux para os ambientes no pavimento intermediário (Figuras 14 a 17). Na orientação sudoeste a diferença de desempenho de acordo com o cenário é mais acentuada com a proximidade da abertura. As zonas mais distantes da abertura, mais especificamente os três últimos pontos do ambiente, apresentam diferença quase nula (Figura 14).

A curva de eUDI no Modelo 1 (cenário atual) atingiu valor máximo de $71 \%$, quando os edifícios do entorno possuem elementos de proteção solar, desempenho similar ao obtido com o cenário isolado (Modelo 2) de 74\%. Comparando com o Modelo 3, os percentuais de eUDI apresentaram redução significativa, especialmente quando o coeficiente de reflexão do entorno é menor (Modelo 3A). A inserção de elementos de proteção horizontal no entorno tende a reduzir os percentuais de eUDI.

Os ambientes localizados na orientação sudeste obtiveram diferenças pouco significativas em relação à sudoeste, sobretudo próximo à janela. $\mathrm{O}$ alcance da luz natural se limita ao terceiro ponto. As iluminâncias excessivas estão relacionadas com as iluminâncias autônomas - aUDI, conforme a Figura 13. Elevados percentuais de aUDI correspondem a percentuais mais baixos de eUDI (Figura 15).

$\mathrm{Na}$ orientação noroeste também se observa o decréscimo de eUDI, principalmente nos cenários com obstrução do entorno (Modelos 3A e 3B). A eUDI passa de $68 \%$ no Modelo 2 (cenário isolado) para 38\% no Modelo 3A (Figura 16a). Destaca-se ainda o efeito dos elementos de proteção solar horizontais presentes nas fachadas dos cenários de ocupação máxima, que tendem a aumentar os níveis de eUDI, especialmente os dispositivos de maior dimensão (Figura 16b).

$\mathrm{Na}$ orientação nordeste os cenários com obstrução e refletividade das fachadas provocaram um decréscimo em menor grau na eUDI, com máximo de $69 \%$ e mínimo de $60 \%$ para os Modelo 2 e Modelo 3A respectivamente (Figura 17a). Já nos cenários com proteção solar nas fachadas 0 Modelo 3B com proteção de $50 \mathrm{~cm}$ apresentou o maior percentual de eUDI, atingindo $67 \%$, e o Modelo 3A, com dispositivo de mesma dimensão, reduziu a eUDI pela metade, atingindo $36 \%$ (Figura 17b). 
Figura 14 - Iluminância natural excessiva (eUDI $>3000$ l lux) - orientação sudoeste

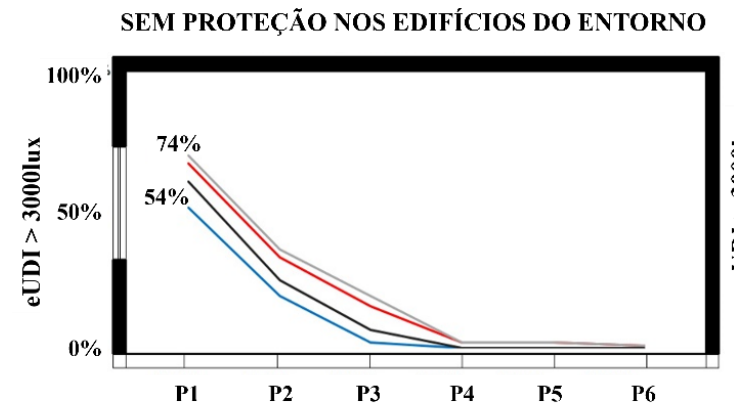

(a)

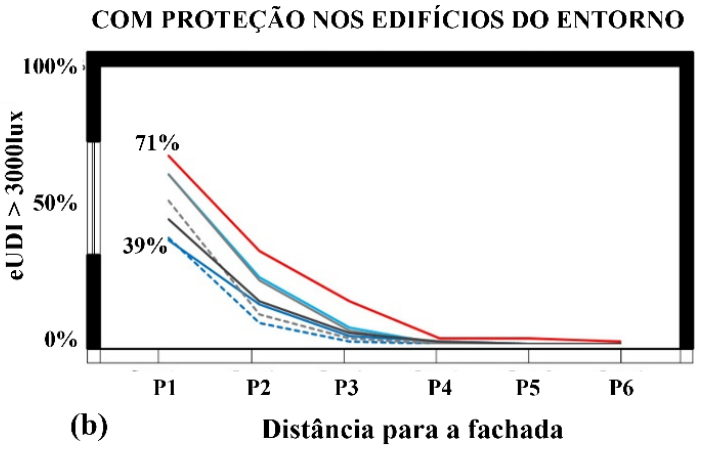

(b)

$$
\begin{array}{llll}
\text { - MODELO } 1 \text { - MODELO } 2 & - \text { MODELO 3A - MODELO 3B } \\
\text { - MODELO 3A P50 } & \cdots \text { MODELO 3A P100 } & \text { - MODELO 3A P150 } \\
\text { - MODELO 3B P50 } \cdots . . \text { MODELO 3B P100 } & \text { MODELO 3B P150 }
\end{array}
$$

Figura 15 - Iluminância natural excessiva (eUDI >3000I lux) - orientação sudeste SEM PROTEÇão NOS EDIFÍCIOS DO ENTORNO COM PROTEÇÃO NOS EDIFÍCIOS DO ENTORNO

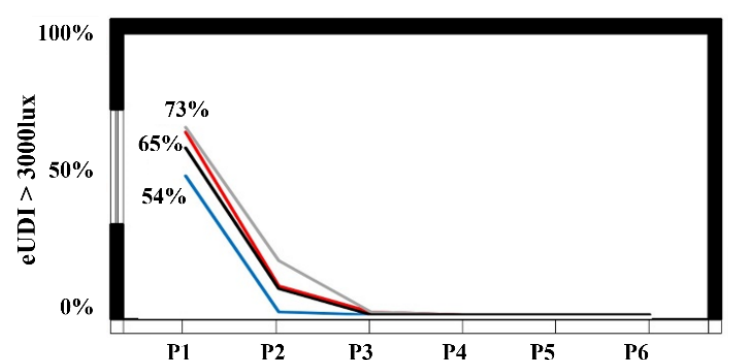

(a) Distância para a fachada

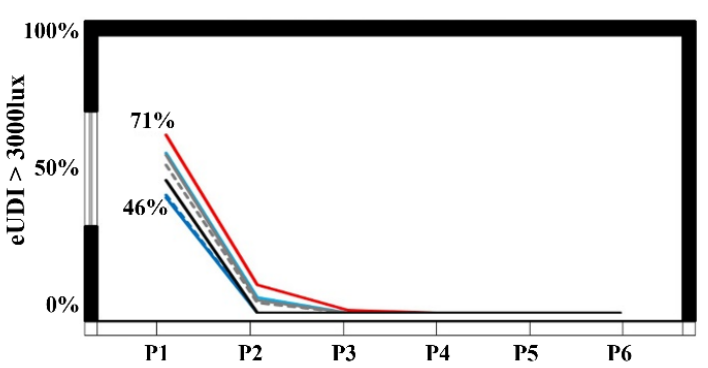

(b)

$$
\begin{aligned}
& \text { - MODELO } 1 \text { - MODELO } 2-\text { MODELO 3A - MODELO 3B } \\
& \text { - MODELO 3A P50 } \ldots . . \text { MODELO 3A P100 - MODELO 3A P150 }
\end{aligned}
$$

Figura 16 - Iluminância natural excessiva (eUDI >3000I lux) - orientação noroeste

SEM PROTEÇÃO NOS EDIFÍCIOS DO ENTORNO

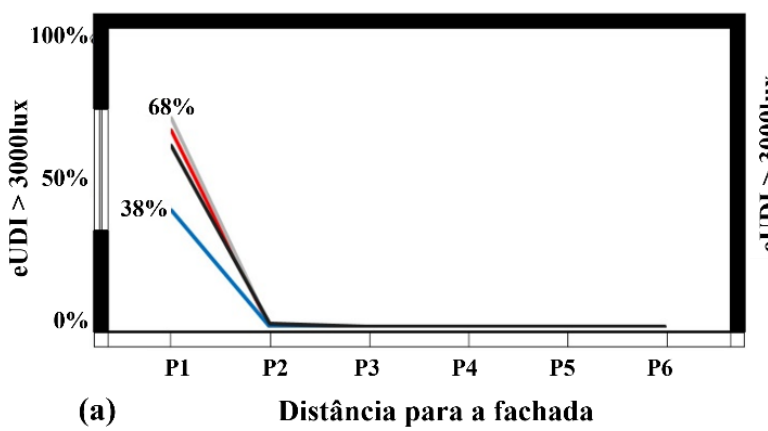

COM PROTEÇÃO NOS EDIFÍCIOS DO ENTORNO

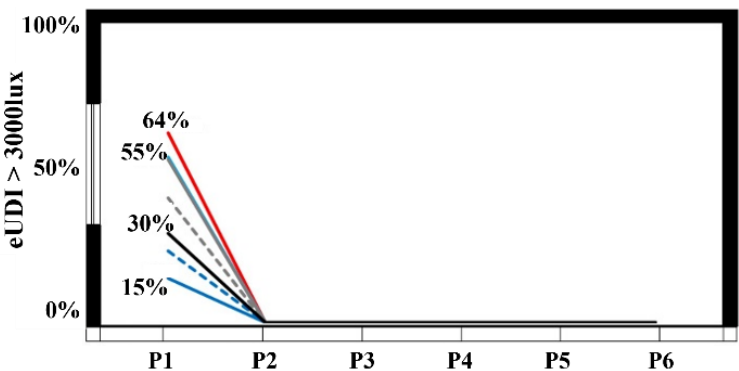

(b)

Distância para a fachada 
Figura 17 - Iluminância natural excessiva (eUDI >3000I lux) - orientação nordeste

SEM PROTEÇÃO NOS EDIFÍCIOS DO ENTORNO

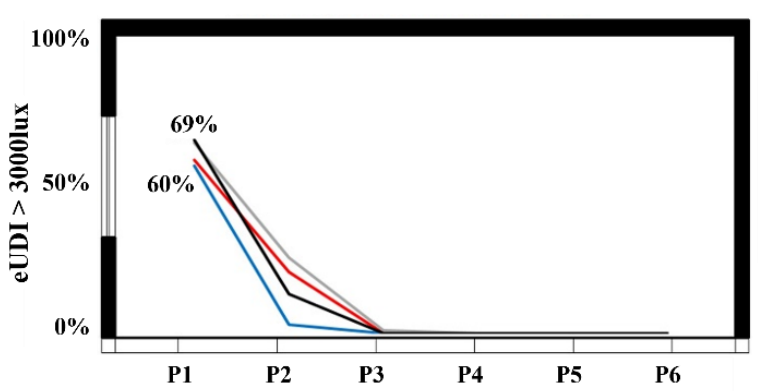

(a)

Distância para a fachada
COM PROTEÇÃO NOS EDIFÍCIOS DO ENTORNO

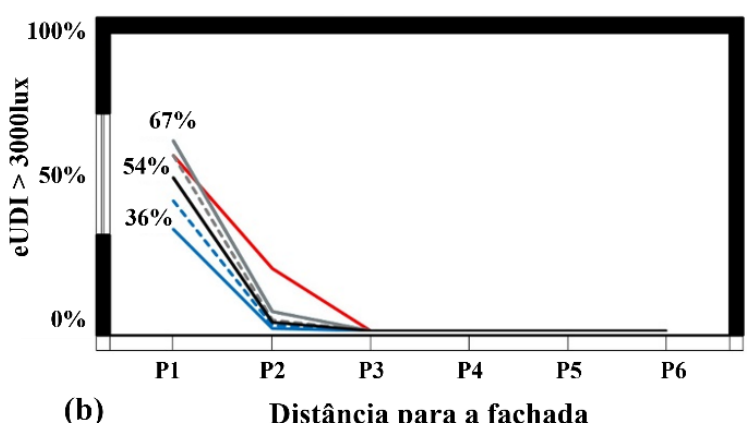

(b) Distância para a fachada

\section{- MODELO $1-$ MODELO $2-$ MODELO 3A - MODELO 3B \\ - MODELO 3A P50 .... MODELO 3A P100 - MODELO 3A P150 \\ — MODELO 3B P50 $\cdots$ MODELO 3B P100 - MODELO 3B P150}

\section{Probabilidade de Ofuscamento da Luz Natural}

O parâmetro probabilidade de ofuscamento da luz natural (Daylight Glare Probability - DGP) foi avaliado em função das variáveis do entorno. Através dos boxplots, observa-se a distribuição geral dos dados com os valores máximos e mínimos da DGP expressos na extremidade e as ocorrências discrepantes, os dados espúrios, dispostos com mais frequência na posição superior da caixa (Figura 18).

Os valores posicionados abaixo do $1^{\circ}$ quartil correspondem aos pontos mais afastados das aberturas (períodos de maior contraste entre o ambiente interno e o externo), que ocorreram no início da manhã e no final da tarde. Os registrados acima do $4^{\circ}$ quartil foram frequentes nos pontos próximos às aberturas (áreas de maior visibilidade do ambiente externo), principalmente nos horários próximos ao meio-dia. Essas observações atípicas foram equivalentes a aproximadamente $2 \%$ da amostra.

Observa-se pequena diferença entre a DGP dos Modelos 1 e 2, sobretudo nas medianas, com valores de $30 \%$ e menos de $25 \%$, que correspondem a percentuais acima da classificação de ofuscamento intolerável. Os ambientes no Modelo 3A apresentaram 98\% dos dados abaixo do limiar de ofuscamento desconfortável, exceto os dados espúrios. Cinquenta por cento dos dados variaram entre $21 \%$ e $35 \%$ no ofuscamento imperceptível, com variação de medianas pouco significativas entre os modelos com e sem proteção solar nas fachadas, sob condição de mesmo cenário. Diferentemente dele, o Modelo 3B apresenta distribuição similar aos Modelos 1 e 2. A adoção de $90 \%$ de refletividade culmina no aumento da DGP quando comparado aos modelos de reflexão de $58 \%$. Pelas medianas observa-se diminuição gradativa da DGP com adoção de proteção solar nos edifícios do entorno, com destaque para a de maior dimensão.

Considerando que o desempenho da DGP nos Modelos 1 e 2 é semelhante, tomou-se como referência o primeiro. Os percentuais de ofuscamento imperceptível (entre $25 \%$ e $35 \%$ ) podem ser observados em todos os cenários, com destaque para o Modelo 3A (com e sem proteção solar no entorno), com aproximadamente $1.500 \mathrm{~h}$. Já os registros mais evidentes de ofuscamento perceptível apresentam maior frequência nos ambientes inseridos no Modelo 1 (entre $400 \mathrm{~h}$ e 500 h) e nos ambientes do Modelo 3B (refletância máxima e sem proteção solar nos edifícios do entorno) com 300 h e 450 h (Figura 19).

Em relação ao ofuscamento desconfortável, os ambientes do Modelo 1 apresentam maior frequência (400 h a 800 h). A refletância média e elementos de proteção solar horizontal nos edifícios do entorno reduzem o ofuscamento, com índice desconfortável inferior a $300 \mathrm{~h}$. Verifica-se acréscimo no ofuscamento com a predominância das cores claras no entorno, diferente da proteção solar, que desempenha papel atenuador. 
Figura 18 - Distribuição (Boxplot) da probabilidade de ofuscamento da luz natural nos cenários

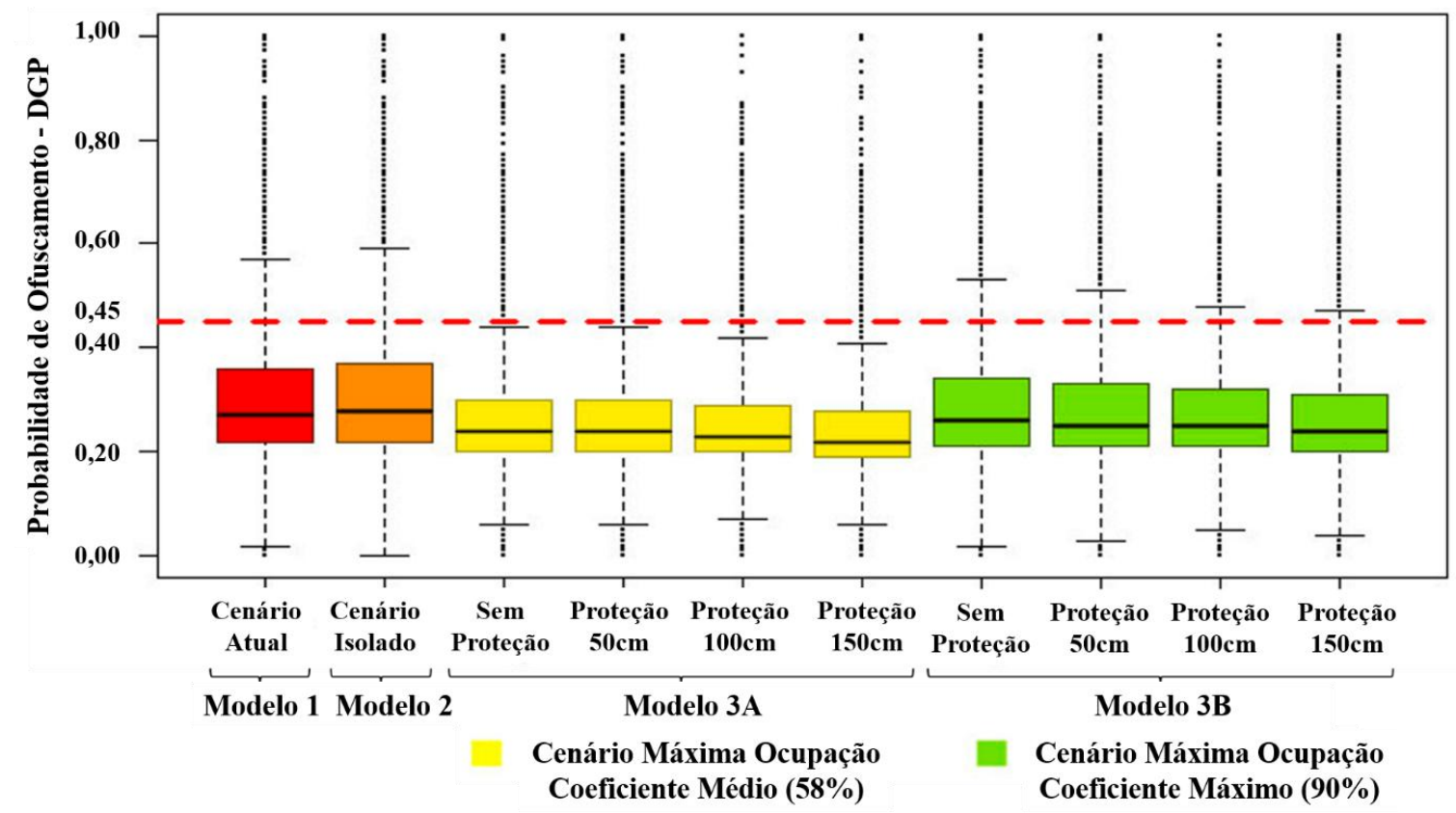

Figura 19 - Frequência de ocorrência horária da probabilidade de ofuscamento - cenários

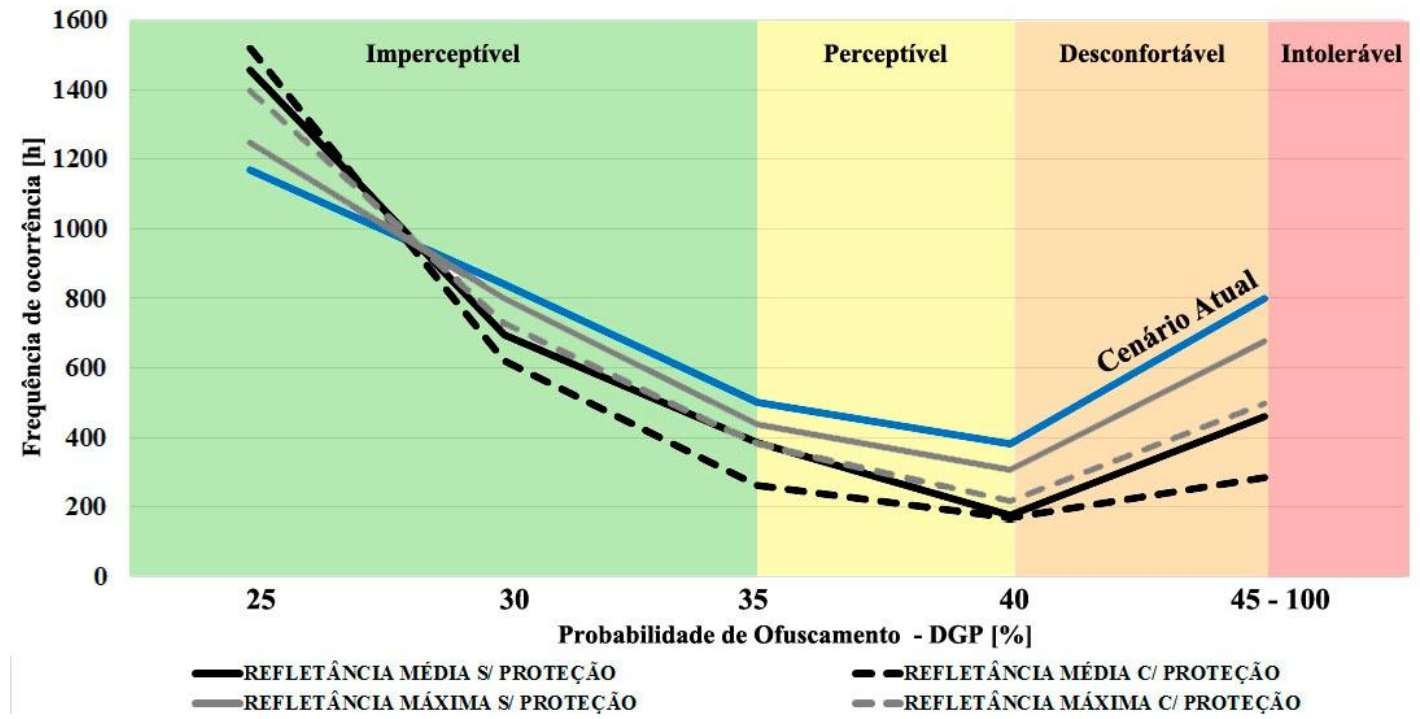

O grau de associação da probabilidade de ofuscamento em condições distintas de cenário, proteção, orientação e pavimento está expresso pelo modelo de regressão logística múltipla. As variáveis categóricas de referência adotadas foram: Modelo 1 (cenário atual), os edifícios do entorno sem proteção (P0), a orientação sudoeste (SO) e o nível de piso térreo $(\mathrm{T})$. Também foram estimados a constante (intercepto), os coeficientes dos parâmetros de análise e os resultados do teste de Wald, representado por $\operatorname{Pr}(>|z|)$, cuja condição de hipótese nula comprova a chance de igualdade entre variáveis para valores $p$ registrados acima do nível de significância adotado $(\mathrm{p}>0,05)$. Entre as variáveis, o primeiro modelo logístico indicou chances de igualdade entre a ocorrência de ofuscamento nos ambientes dos Modelos 1 e 2, de acordo com o valor $p$ de 0,1369. Diante da similaridade de resultados, foi elaborado o modelo logístico simplificado (Equações 3 e 4 e Tabela 8), considerando os referidos cenários como uma única variável categórica.

$$
\begin{aligned}
& \ln \left(\frac{p(\text { sucesso })}{1-p(\text { sucesso })}\right)=-1,99-0,58 \mathrm{M} 3 \mathrm{~A}-0,14 \mathrm{M} 3 \mathrm{~B}- \\
& 0,08 \mathrm{P} 50-0,25 \mathrm{P} 100-0,39 \mathrm{P} 150+0,52 \mathrm{SE}+ \\
& 0,08 \mathrm{NO}-0,32 \mathrm{NE}+0,39 \mathrm{I}+0,82 \mathrm{C} \quad \mathrm{Eq} .3
\end{aligned}
$$


Razão da chance $={ }_{e}(-1,99-0,58 \mathrm{M} 3 \mathrm{~A}-0,14 \mathrm{M} 3 \mathrm{~B}-$ 0,08P50-0,25P100-0,39P150+0,52SE+0,08NO-

$0,32 \mathrm{NE}+0,39 \mathrm{I}+0,82 \mathrm{C})$

Eq. 4

Verifica-se a razão da chance (Odds Ratio) estimada em percentuais de ocorrência de ofuscamento mediante alteração das variáveis explicativas (cenário, proteção, orientação e pavimento). A chance de ocorrer ofuscamento reduziu em $58 \%$ e em $34 \%$ nos ambientes inseridos nos cenários de máxima ocupação com refletância média nas fachadas (Modelo 3A) e máxima (Modelo 3B) respectivamente. A diferença observada se deve exclusivamente à refletividade, tendo menor probabilidade os ambientes que possui coeficiente médio. Quanto mais obstruído o entorno e quanto menor o coeficiente de reflexão das fachadas menor a DGP.

Para a proteção solar nos edifícios do entorno, as estimativas dos coeficientes apontam valores negativos com decréscimo na ocorrência de ofuscamento mediante inserção de elementos de proteção. Os dispositivos com dimensão de $50 \mathrm{~cm}$, $100 \mathrm{~cm}$ e $150 \mathrm{~cm}$ reduzem a probabilidade de ofuscamento em $8,6 \%, 23 \%$ e $33 \%$ respectivamente. $\mathrm{O}$ modelo logístico e a razão das chances comprovam a influência da proteção do entorno na redução da DGP, sendo esta proporcional à dimensão do dispositivo.

As estimativas para orientação revelam aumento da chance de ofuscamento para os ambientes nas fachadas sudeste e noroeste, respectivamente $69,5 \%$ e $8,5 \%$, com redução de $29 \%$ para a fachada nordeste. $\mathrm{O}$ aumento na chance de ofuscamento é de $47,8 \%$ no pavimento intermediário e de 2,2 vezes na cobertura. Nesse sentido, um ambiente com orientação sudeste e na cobertura apresenta maior probabilidade de ofuscamento quando comparado às referências sudoeste e térreo.

\section{Conclusões}

Neste trabalho realizou-se uma investigação sobre a influência do entorno no desempenho lumínico e visual em ambientes internos localizados em região de clima tropical, considerando usuários passivos. Os procedimentos da pesquisa envolvem métricas dinâmicas da luz natural através de simulação computacional e tratamento dos dados com testes de hipóteses e modelos estatísticos de regressão.

Tabela 8 - Modelo logístico simplificado

\begin{tabular}{|c|c|c|c|c|c|}
\hline Parâmetros & Estimativas & $\operatorname{Pr}(>|z|)$ & $\begin{array}{l}\text { Resultado } \\
\text { Wald }\end{array}$ & \multicolumn{2}{|c|}{ Razão da chance (Odd Ratio) } \\
\hline Constante (intercepto) & $-1,99809$ & $<2 \mathrm{e}-16$ & Rejeita a Ho & 0,1355941 & Redução em $76 \%$ \\
\hline $\begin{array}{l}\text { Cenários atual e isolado - } \\
\text { Referência }\end{array}$ & - & - & - & - & - \\
\hline $\begin{array}{l}\text { Máxima ocupação reflexão } \\
58 \% \text { (M3A) }\end{array}$ & $-0,58687$ & $<2 \mathrm{e}-16$ & Rejeita a Ho & 0,5560659 & Redução em $58 \%$ \\
\hline $\begin{array}{l}\text { Máxima ocupação reflexão } \\
\text { 90\% (M3B) }\end{array}$ & $-0,14596$ & 0,000676 & Rejeita a Ho & 0,8641959 & Redução em 34\% \\
\hline $\begin{array}{l}\text { Sem proteção }(\mathrm{P0}) \text { - } \\
\text { Referência }\end{array}$ & - & - & - & - & - \\
\hline $\begin{array}{l}\text { Proteção } 50 \mathrm{~cm} \text { no entorno } \\
\text { (P50) }\end{array}$ & $-0,08904$ & 0,040870 & Rejeita a Ho & 0,9148120 & Redução em 8,6\% \\
\hline $\begin{array}{l}\text { Proteção } 100 \mathrm{~cm} \text { no } \\
\text { entorno (P100) }\end{array}$ & $-0,25356$ & $1,65 \mathrm{e}-08$ & Rejeita a Ho & 0,7760346 & Redução em $23 \%$ \\
\hline $\begin{array}{l}\text { Proteção } 150 \mathrm{~cm} \text { no } \\
\text { entorno }(\mathrm{P} 150)\end{array}$ & $-0,39349$ & $<2 \mathrm{e}-16$ & Rejeita a Ho & 0,6747008 & Redução em 33\% \\
\hline $\begin{array}{l}\text { Orientação sudoeste (SO) } \\
\text { - Referência }\end{array}$ & - & - & - & - & - \\
\hline Orientação sudeste (SE) & 0,52750 & $<2 \mathrm{e}-16$ & Rejeita a Ho & 1,6946929 & Aumento em $69,5 \%$ \\
\hline Orientação noroeste (NO) & 0,08240 & 0,038522 & Rejeita a Ho & 1,0858908 & Aumento em $8,5 \%$ \\
\hline Orientação nordeste (NE) & $-0,32914$ & $2,36 \mathrm{e}-14$ & Rejeita a Ho & 0,7195421 & Redução em $29 \%$ \\
\hline $\begin{array}{l}\text { Pavimento térreo }(\mathrm{T})- \\
\text { Referência }\end{array}$ & - & - & - & - & - \\
\hline Pavimento intermediário (I) & 0,39134 & $<2 \mathrm{e}-16$ & Rejeita a Ho & 1,4789563 & Aumento em $47,8 \%$ \\
\hline Pavimento cobertura (C) & 0,82688 & $<2 \mathrm{e}-16$ & Rejeita a Ho & 2,2860515 & Aumento em 2,2 vezes \\
\hline
\end{tabular}

114 LEAL, L. de Q.; LEDER, S. M. 
Os ambientes inseridos nos cenários de máxima ocupação (Modelo 3) apresentaram menor probabilidade de ofuscamento e redução nos percentuais de iluminância autônoma (aUDI $_{300-}$ 3000lux). Já nos cenários atual e isolado (Modelos 1 e 2) foram registrados maiores níveis, contraste e índices de ofuscamento. Nos ambientes do cenário de máxima ocupação com reflexão média e máxima no entorno (Modelos 3A e 3B) a área iluminada (aUDI) foi reduzida em $21,5 \%$ e $13 \%$ respectivamente. Os pavimentos inferiores foram mais afetados pela obstrução do entorno, tomando como referência as medianas, e, em relação aos pavimentos mais altos (intermediário e cobertura), apresentaram redução da iluminação de $15 \%$ e $40 \%$ respectivamente. O percentual de área iluminada e o desconforto visual alcançaram maiores proporções nos pavimentos mais elevados.

Sobre a probabilidade de ofuscamento, nos Modelos 1 e 2 aproximadamente $25 \%$ dos dados estão associados ao ofuscamento intolerável (>45\%), e no Modelo 3A 98\% dos dados estão abaixo do limiar de ofuscamento desconfortável, com pouca variação entre os modelos com e sem proteção solar nas fachadas. Já o Modelo 3B apresenta ofuscamento similar àquele encontrado nos Modelos 1 e 2, em especial os modelos sem proteção solar nas fachadas do entorno. Comparando com o Modelo 1 (cenário atual), a chance de ocorrer ofuscamento reduziu em $58 \%$ e $34 \%$ nos ambientes inseridos nos cenários de maior obstrução com fachadas de refletância média e máxima (Modelo 3A e 3B) respectivamente. A diferença se deve exclusivamente à reflexão, tendo menor chance de ofuscamento os ambientes sob influência do entorno de reflexão média.

Comparando os modelos de máxima ocupação em relação ao coeficiente de reflexão, o Modelo 3B contribuiu para o aumento da área iluminada dos ambientes em 8,5\%. Todavia, acrescenta apenas $3 \%$ na iluminação no pavimento térreo, e para o pavimento intermediário o acréscimo é maior, em torno de $7 \%$. Na cobertura, o coeficiente de reflexão de $90 \%$ minimizou a influência do sombreamento causado pela obstrução do entorno.

A adoção de elementos de proteção solar horizontal no entorno resultou na uniformidade da iluminação e na redução das iluminâncias excessivas e do ofuscamento, fator oportuno em locais de baixa latitude, reiterando pesquisas anteriores (LAM, 1986; HOPKINSON; PETHERBRIDGE; LONGMORE, 1966; CABÚS, 2004). Observou-se crescimento gradativo da iluminância na faixa útil proporcional ao aumento da dimensão do dispositivo, confirmado pelos testes de hipóteses. No Modelo 3A, cujo cenário de máxima ocupação tem coeficiente de reflexão médio (58\%), registraram-se acréscimos de 3,6\%, $10,5 \%$ e $19,91 \%$ nas estimativas das áreas iluminadas (aUDI) para proteções de $0,50 \mathrm{~m}, 1,00$ $\mathrm{m}$ e $1,50 \mathrm{~m}$ respectivamente. Ainda, esses dispositivos atenuaram gradativamente o DGP em $8,6 \%, 23 \%$ e $33 \%$ para proteções de $50 \mathrm{~cm}, 100$ $\mathrm{cm}$ e $150 \mathrm{~cm}$ respectivamente, ratificado pelo modelo logístico e pela razão das chances.

Considerando que o clima tropical representa grande parte do território brasileiro e que o recorte urbano estudado é uma solução urbana recorrente, entende-se que esses resultados se aplicam a muitas cidades brasileiras. Como sugestões para trabalhos futuros, outras variáveis devem ser exploradas, tais como a interferência de usuários ativos, diferentes coeficientes de reflexão no exterior e o impacto do uso de proteção solar no próprio edifício, já que esta é uma solução recomendada para o clima tropical.

\section{Referências}

\section{ASSOCIAÇÃO BRASILEIRA DE NORMAS}

TÉCNICAS. NBR 15220: desempenho térmico de edificações: parte 3: zoneamento bioclimático brasileiro e diretrizes construtivas para habitações unifamiliares de interesse social .Rio de Janeiro, 2005.

ASSOCIAÇÃO BRASILEIRA DE NORMAS TÉCNICAS. NBR 15215: iluminação natural: parte 3: procedimento de cálculo para a determinação da iluminação natural em ambientes internos. Rio de Janeiro, 2005.

BAKER, N.; FANCHIOTTI, A.; STEEMERS, K.Daylighting in Architecture. London: James \& James, 1993.

CABÚS, R. et al. Influência da Luz Refletida no Solo na Iluminação Natural em Edifícios Com Vários Pavimentos nos Trópicos. In: ENCONTRO NACIONAL E LATINO AMERICANO DE CONFORTO NO AMBIENTE CONSTRUÍDO, Maceió, 2005. Anais... Maceió, 2005.

CHATZIDIMITRIOU, A.; YANNAS, S. Microclimatic Studies of Urban Open Spaces in Northenrn Greece. In: INTERNATIONAL CONFERENCE ON PASSIVE AN LOW ENERGY ARCHITECTURE, 21., Eindhoven, 2004. Proceedings... Eindhoven: PLEA, 2004.

CIBSE. The Chartered Institution of Building Services Engineers. In: LIGHTING Guide 11: surface reflectance and colour.London: Society of Light and Lighting, 2001. Report LG11. 
COMPAGNON, R. Solar and Daylight Availability in the Urban Fabric. Energy and Buildings, London, v. 36, p. 321-328, 2004.

GOOGLEMAPS. [Mapas]. Disponível em: <https://www.google.com.br/maps>. Acesso em: 22 jan. 2018.

HOPKINSON, R. G.; PETHERBRIDGE, P.; LONGMORE, J. Iluminação Natural. Lisboa: Fundação Calouste Gulbenkian, 1966.

JAKUBIEC, A.; REINHART, C. The Use of Glare Metrics in the Design of Daylit Spaces: recommendations for practice.In: INTERNACIONAL RADIANCE WORKSHOP, 9., Freiburg, 2010. Proceedings... Freiburg: Harvard Design School, 2010.

JOHNSON, R. A.; WICHERN, D. W. Applied Multivariate Statistical Analysis. 6. ed. New Jersey: Prentice-Hall, 2007.

LAM, W. C. Sunlighting as Formgiver For Architecture. New York: Van Nostrand Reinhold, 1986.

LEAL, L. de Q. Influência das Variáveis de Entorno e do Edifício Sobre as Iluminâncias e o Ofuscamento nos Ambientes Internos: um estudo de caso em edifícios residenciais multipavimentos em recorte urbano na cidade de João Pessoa/PB. Programa de Pós-graduação em Arquitetura e Urbanismo, Universidade Federal da Paraíba, 2013.

LEDER, S. M.; PEREIRA, F. O. R.; CLARO, A. Janela de Céu Preferível: proposição de um parâmetro para controle da disponibilidade de luz natural no meio urbano. Ambiente Construído, Porto Alegre, v. 8, n. 1, p. 89-104, jan./mar. 2008.

LI, D. H. W. et al. Determination of Vertical Daylight Illuminance Under Non-Overcast Sky Conditions. Building and Environment, v. 45, p. 498-508, 2010.

MARDALJEVIC, J. et al.Daylighting Metrics For Residential Buildings. In: SESSION OF THE CIE, 27., Sun City, 2011. Proceedings... Sun City, 2011.

MARDALJEVIC, J. et al. Daylighting Metrics: is there a relation between useful daylight illuminance and daylight glare probability. In: BUILDING SIMULATION AND OPTIMIZATION CONFERENCE, 1 ., Loughborough, 2012. Proceedings... Loughborough, 2012.
MESA, N. A. et al. Metodologia de Evaluacion de la Potencialidad de la Luz Natural Para Iluminar Edifícios, en Entornos de Alta Densidad, en Zonas Áridas Andinas. Estúdios de ArquitecturaBioclimática, México, v. 6, p. 279. 297, 2004.

NABIL, A.; MARDALJEVIC, J. Useful Daylight Illuminance: a new paradigm to access daylight in buildings. Lighting Research \& Technology, v. 37, n. 1, 2005.

NG, E. A Study of the Relationship Between Daylight Performance and Height Difference of Buildings in High Density Cities Using Computational Simulation. In: INTERNATIONAL BUILDING PERFORMANCE SIMULATION CONFERENCE, Montreal, 2005. Proceedings... Montreal: IBPSA, 2005.

NG, E.; WONG, N. H. Better Daylight and Natural Ventilation by Design. In: INTERNATIONAL CONFERENCE ON PASSIVE AN LOW ENERGY ARCHITECTURE, Singapore, 2004. Proceedings... Singapore: PLEA, 2004.

ORAL, G. K.; YENER, A. K.; BAYAZIT, N. T. Building Envelope Design With the Objective to Ensure Thermal, Visual and Acoustic Comfort Conditions. Building and Environment, London, v. 39, p. 281-287, 2004.

PREFEITURA MUNICIPAL DE JOÃO PESSOA. Secretaria de Planejamento. [Fotos]. João Pessoa, 2012.

RATTI, C.; BAKER, N.; STEEMERS, K. Energy consumption and urban texture. Energy and buildings, v. 37, p. 762-776, 2005.

REINHART, C. Daylighting Handbook I: fundamentals, designing with the sun. 2014.

REINHART, C. F. A Simulation-Based Review of the Ubiquitous Window-Head-Height to Daylit Zone Depth Rule-of-Thumb. In:

INTERNATIONAL BUILDING SIMULATIONS CONFERENCE, 9., Montreal, 2005.

Proceedings... Montreal: IBPSA, 2005.

REINHART, C. F. Tutorial on the Use of Daysim Simulations For Sustainable Design. Cambridge: Harvard University, 2010.

ROBBINS, C. L. Daylighting: design and analysis. New York: Van Nostrand Reinhold, 1986.

ROGERS, Z. Daylighting Metric Development Using Daylight Autonomy Calculations in the Sensor Placement Optimization Tool. Boulder: Architectural Energy Corporation, 2006. 
SCALCO, V. A.; PEREIRA, F. O. R. Método Para a Avaliação do Impacto de Edificações no Acesso à Iluminação Natural em Vizinhanças Urbanas Aplicado em Cenários Virtuais. Ambiente Construído, Porto Alegre, v. 16, n. 2, p. 169-187, abr./jun. 2016.

SCALCO, V. A.; PEREIRA, F. O. R.; CLARO, A. Impacto de Novas Edificações na Vizinhança: proposta de método para a análise das condições de iluminação natural e de insolação. Ambiente Construído, Porto Alegre, v. 10, n. 2, p. 171-187, abr./jun. 2010.

TSANGRASSOULIS, A. et al. A Method to Investigate the Potencial of South-Oriented Vertical Surfaces For Under Sunny Conditions. Solar Energy, v. 66, n. 6, p. 439-446, 1999.
ÜNVER, R. et al. Effect of Facade Alternatives on the Daylight Illuminance in Offices. Energy and Buildings, v. 35, n. 8, p. 737-746, 2003.

WIENOLD, J. Daylight Glare in Offices. Tese (Doutorado) - Fraunhofer Verlag, Alemanha, 2010.

WIENOLD, J.; CHRISTOFFERSEN, J.

Evaluation Methods and Development of a New Glare Prediction Model For Daylight Environments With the Use of CCD

Cameras.Energy \& Buildings, v. 38, n. 7, p. 743757, 2006.

WONG, N. H.; ISTIADJI, A. D. Effects of External Shading Devices on Daylighting and Natural Ventilation. In: INTERNATIONAL IBPSA CONFERENCE EINDHOVEN, 8., Eindhoven, 2003. Proceedings... Eindhoven, 2003.

\title{
Lilianne de Queiroz Leal
}

Unidade Acadêmica de Ciências e Tecnologia Ambiental, Centro de Ciêmcias e Tecnologia Agroalimentar | Universidade Federal de Campina Grande | Rua Jairo Vieira Feitosa, 1770, Bairro dos Pereiros | Pombal - PB - Brasil | CEP 58840-000 | Tel.: (83) 3431-4000 | Email: liliannequeiroz@hotmail.com

\section{Solange Maria Leder}

Departamento de Arquitetura, Centro de Tecnologia | Universidade Federal da Paraíba | Castelo Branco s/n, Campus I | João Pessoa - PB - Brasil | CEP 58059-900 | Tel.: (83) 3216-7378 | E-mail: solangeleder@yahoo.com.br

\author{
Revista Ambiente Construído \\ Associação Nacional de Tecnologia do Ambiente Construído \\ Av. Osvaldo Aranha, $99-3^{\circ}$ andar, Centro \\ Porto Alegre - RS - Brasil \\ CEP $90035-190$ \\ Telefone: +55 (51) 3308-4084 \\ Fax: +55 (51) 3308-4054 \\ www.seer.ufrgs.br/ambienteconstruido \\ E-mail: ambienteconstruido@ufrgs.br
}

